Review of

ECONOMICS

and

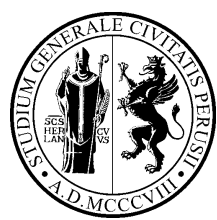

www.rei.unipg.it

\title{
Transitional Forces in a Resource Based Economy: Phases of Economic and Institutional Development in Hawaii
}

\author{
Brooks A. Kaiser $^{\bowtie} \quad$ James A. Roumasset \\ University of Hawaii University of Hawaii
}

\begin{abstract}
We illuminate several important aspects of the nature and causes of growth and institutional change. To do this, we focus on the role resource pressures have played in the historic development of Hawaii's institutions. We discuss the Hawaiian story in the context of the natural co-evolution of production systems, organizational forms and authority structures in a resource dependent economy. We model the resource dependency as a multi-trophic ecologically based system. Productivity is a dynamic function of the available resource, human populations of laborers and wealth (capital) accumulation that funds management and governance through a nonproductive elite class. We use both archeological and historical evidence from natural resource use during the settlement and modernization of the Hawaiian economy. Hawaii's resources are first controlled by hierarchy, which intensifies over time. Decentralization occurs after Western contact (1778), though not immediately. Unlike many existing analyses of primitive economic development, there does not exist a monotonic relationship between population and resource pressure. In a model of second-best resource management, optimal governance changes as the balance between sustenance and other resource uses shifts.
\end{abstract}

JEL classification: P48, N47, N57, Q22, Q01;

Keywords: natural resource dynamics, institutional change, governance of the commons, Hawaiian economic development

$\triangle$ Corresponding author. Address: University of Southern Denmark, Department of Environmental and Business Economics, Niels Bohrs Vej 9-10, 6700 Esbjerg, Denmark. (Phone: +45 6550 1590. Email: baka@sam.sdu.dk)

\section{Recommended Citation}

Kaiser, B.A., Roumasset, J.A., (2014). Transitional Forces in a Resource Based Economy: Phases of Economic and Institutional Development in Hawaii. Review of Economics and Institutions, 5(2), Article 2. doi: 10.5202/rei.v5i2.118. Retrieved from http://www.rei.unipg.it/rei/article/view/118 


\section{Introduction}

Using both archeological and historical evidence from natural resource use during the settlement and modernization of the Hawaiian economy, we discuss the role resource pressure has played in the historic development of many of Hawaii's institutions. Through this lens we discuss an analytical framework that illuminates several important aspects of the nature and causes of growth and institutional change. Simple economies provide opportunities for insights into economic theory that are more difficult to disentangle in more complex modern economies (e.g. Fisk and Shand, 1970; Brander and Taylor, 1998; Taylor, 2011). Such simple cases, however, often lack sufficiently delineable evidence covering the range of evolutionary pressures needed to inform broadly across a developmental spectrum. For example, in many models of simple cases, resource development is inextricably and monotonically linked to population dynamics. This is potentially misleading in that these models do not allow much scope for shifts in such important dynamic factors in resource use as trade opportunities, technological progress, or development of a ruling elite class. Hawaii's relatively well documented and dramatic transition from a resource based primitive Polynesian culture through its economic and institutional integration into the United States provides a unique opportunity to investigate the dynamic relationships between a resource base and the population using it, including governance and institutional structures.

We merge two strands of literature to investigate these dynamics. From New Institutional Economics, we draw on theories of costs and benefits of governance and institutional change. From resource economics, we draw on ecological models of resource dependency. Together, these allow construction and exploration of a dynamic model of a resource-based economy in which governance co-evolves with production, specialization, and population. We focus our effort by categorizing the physical evidence brought forward by Kirch and his interdisciplinary team of researchers on Hawaiian history into three primary phases: extensive growth, intensive growth and capitalization, and decentralization, as well as the transitions amongst them $\sqrt[1]{1}^{1}$ We discuss the dynamics of natural resource governance, informed by the Hawaii case.

\footnotetext{
1 As we do, these researchers choose Hawaii because:

"the archipelago... presents an ideal region for understanding complex interactions between human populations and their environments. In Hawaii such interactions can be tracked over a time frame of about 1200 years. During this period between the discovery and colonization of the archipelago by humans and the arrival of Europeans, archaeological research reveals the emergence of a highly complex island civilization which by A.D. 1700 had approached the level of an "archaic state." In Hawaii, historical anthropologists and natural scientists have the opportunity to study the emergence of such complexity in the context of dynamic coupling with natural systems." (Kirch, 2007)
} 
A formal model elucidates in Appendix 1.2 The model presents an economic system in which a resource stock is harvested and expanded for use by a stratified human population, subject to constraints that have dynamic feedback effects on the stock. These constraints are due to the costs of governing harvest. The stock is harvested for three purposes: consumption by the (endogenous) laborer portion of the population, export, and/or capital (wealth) accumulation that funds an elite governing class. The elite class does not contribute directly to production and is considered, in the language of ecology, a 'top predator.' They may, however, choose to use the wealth accumulation as capital to increase the base resource carrying capacity and subsequently the resource stock (through infrastructure investments and/or technological progress, which work separately in the model). This use of capital allows for reduction in intraspecific competition of the human population (e.g. through territorial expansion into unused resources). The model incorporates changes in (exogenous) resource values, harvesting and governance costs for common property resources, and costs of enforcing resource use for wealth accumulation (e.g. protecting an elite class) and/or trade (e.g. regulation of markets) in order to explore the co-evolution of governance structures and resource pressures. In our exploration, we present sparse evidence substantiating stylized facts about Hawaiian economic development, and expand the discussion into the historic era, where Hawaiian economic development shifts rapidly, though not uniformly, from hierarchical control to decentralized decision-making.

\section{Dynamic Theory of Resource Use and Institu- tional Change}

We begin with an exposition of the Hawaii case. By elucidating this evidence, we garner the key factors with which any model must be consistent if it is to explain extensive growth, intensive growth, and decentralization in resource use for a resource based economy. The isolation of the Hawaiian archipelago meant that there were severe limitations in providing new technologies or trade opportunities for much of its development, and this allows for clear insights into the intertwined relationship between institutional change and stages of growth.

\subsection{Archaeological and Historical Record in the Context of Development}

In the Hawaiian context, upon arrival of the Polynesians, virtually all sustenance came from the sea and from a limited stock of flightless birds. The initial marine resource base can thus be considered to have been at car-

2 http://www.rei.unipg.it/rei/rt/suppFiles/118/0 
rying capacity for marine resources. Most land resources, however, were derived from small stocks, at or close to the minimum viable population after a long sea voyage, arriving with the humans. These consisted most notably of pigs, dogs, chickens, rats, taro, sweet potatoes, yams, bananas, coconut palms, sugar cane, and breadfruit. Their establishment and propagation required labor and some governance from the first. Flexible governance options to match these disparate situations were required if a single hierarchical institutional structure, or set of governance rules, such as the Polynesians had imported as well, were to govern.

Before trade, technological progress was extremely limited by the absence of such resources as metals, energy sources, and beasts of burden.$^{3}$ This separation of gains from trade and gains from capitalization is a large part of what makes the Hawaiian case so useful in elucidating our model. The main gains from capitalization came through governance: hierarchicallyorganized labor used to expand the sustenance resource base. In particular, hierarchical management enabled the transformation of wet, windward valleys into self-sufficient integrated resource use communities through the ahupua'a (mountain-to-ocean watershed district) management system. Gains from specialization and intensification in this system could be, and were, at times, dissipated by rent-seeking elites who governed them. This integrated production and governance system evolved in response to irrigation needs for the transplanted taro, and covered all aspects of land and marine resource use and development. Details of the ahupua' $a$ system are discussed in Appendix 2.

After Western contact in 1778, the main gains from trade came from resources that differed from those most traditionally used for sustenance. Significant population decline, primarily from the exogenous shock of disease with the arrival of Westerners, also significantly reduced the value of resources for sustenance at just the time that they became increasingly valuable in trade. We can identify shifts in crops as a function of these changes in land resources, and as expected from our model, we can identify shifts in harvest governance intensity for marine resources as a function of these shifting resource values.

The standard division in Hawaiian history between the pre-historic record (until Western Contact) and the historic record masks the underlying pressures affecting the rapid institutional change that occurred following Western Contact. We instead divide Hawaiian history into three phases, with overlapping transitional periods between them. They are: (1) Extensive Growth, encompassing the archaeologists' Colonial, Development, and

\footnotetext{
${ }^{3}$ Note, for example, that the only land mammal to arrive in HI without human-assisted transport was the Hawaiian Hoary Bat. Biomass for fires was available from forests and drylands, but evidence from later $19^{\text {th }}$ century use for whale blubber rendering shows that this rapidly depleted the forests, along with damages from newly introduced ungulate species. Clearly this resource was also limited and fragile (Kuykendall, 1938).
} 
Expansion periods (c. 400 AD-1650 AD); (2) Intensive Growth and Capitalization, encompassing the Expansion, Proto-Historic, Unification and Independent Kingdom periods (c. 1450 AD-1900 AD), and (3) Trade, beginning with Western contact and continuing through significant population decline, increased opportunities for trade, and institutional shifts to private property (1778-present) (Kirch, 1985). These phases are illustrated in Figure 1 , and further described in Appendix 3. Note that Western Contact is not the primary focus here because the development path finds continuity of the co-evolution of specialization and hierarchy before private property, while the structural break in institutions toward private property is also shown as a progression and de-coupling of growth effects driven by separating (decreasing) population pressures and (increasing) trade opportunities. Importantly, the significant population decline after Western Contact does not affect the economy in ways predicted by simpler models of economic development in a resource based economy. This is due to the inclusions of governance, wealth and capital development, and trade as parts of the economic system. The extent and timing of the shifts in private property are marked by differences in decentralization of common property resources as a function of their value. This value accrues beyond mere sustenance.

\section{Figure 1 - Three Phases of Growth in Hawaiian Context}

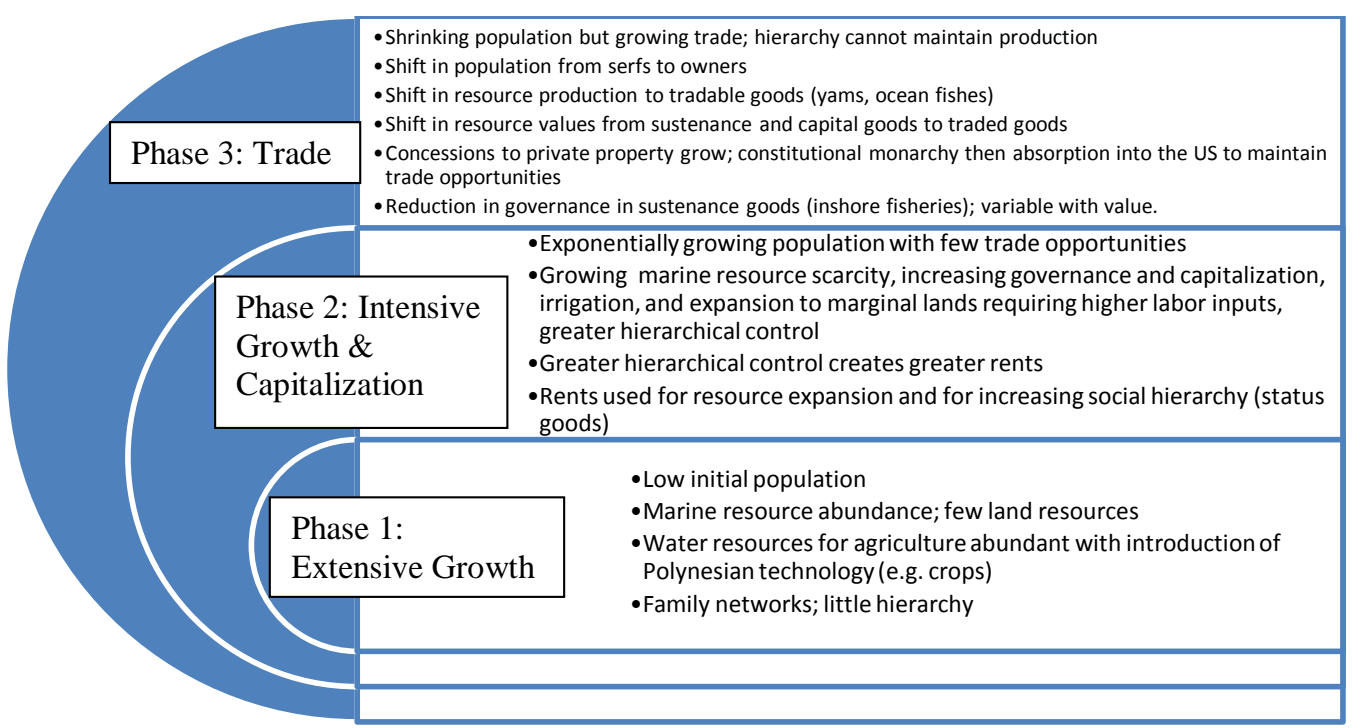

\subsection{Stylized Facts and Synthesis}

We summarize from the archaeological and historical record several stylized facts before and after Western contact that any model of such a resourcebased economy must address:

Before contact: The increase in population before Western contact was 
associated with increasing horizontal specialization and intensification of agricultural production and resource use. Both the control and decisionmaking aspects of governance became more centralized. Social hierarchies were closely aligned with increasingly vertically specialized managerial structures. Specialization was primarily within mostly self-sustaining ahupua'a (mountain-to-ocean watershed district) hierarchies, relative to trade across hierarchies.

Recently constructed long run data on Hawaiian near-shore fisheries productivity from 1200AD forward illustrates that Hawaii's governance structure worked successfully to overcome commons problems. A sustainable, high level of resource extraction for subsistence existed for 600 years (McClenachan and Kittinger, 2013), the latter 350 of which achieved reef resource productivity 2.4 times greater than most current (overexploited) coastal reef fisheries. The time frame encompasses a period of significant population growth (to $1650 \mathrm{AD}$ ), technological shifts in agriculture with an expansion into dryland agriculture after $1450 \mathrm{AD}$, and population stagnation or possibly decline (after 1650 AD), lasting even into the early years post-contact.

After contact: Slightly before Western contact, and increasingly after contact, population declined, but intensification and specialization continued due to the new opportunities afforded by international trade. After first becoming more centralized through consolidation of the islands' chiefdoms into the Hawaiian Kingdom, decision-making became decentralized and private property developed. Specialization across hierarchies developed along with trade.

Figure 2 illustrates these stylized facts. As private property expands, governance costs and government responsibility increase. Private property does not obviate the need for government control. As decision-making is decentralized, growth and development require institutional support for voluntary contractual exchange as well as for resolving externalities and public good problems imposed by the conflicting goals of individual decision-makers. At low levels of scarcity and specialization, centralization of authority and decisions increase together, to reduce idiosyncratic risks through mutual insurance and diversification, and exploit economies of scale in production, e.g. large scale irrigation works. Our goal here is to connect these patterns to the economy's resource base and its governance, in Hawaii, in order to explore the relationship between a resource and technological base and institutional development.

As resource pressures increase, returns to specialization, intensification, capitalization and governance require additional centralization of authority and decision-making, which, in small populations with limited opportunities for external economies of trade, can be developed through hierarchy. With larger populations or a change in opportunities for trade, hierarchy's relative inability to solve relevant information and coordination problems 


\section{Figure 2 - The Political Economy of Resource Governance}

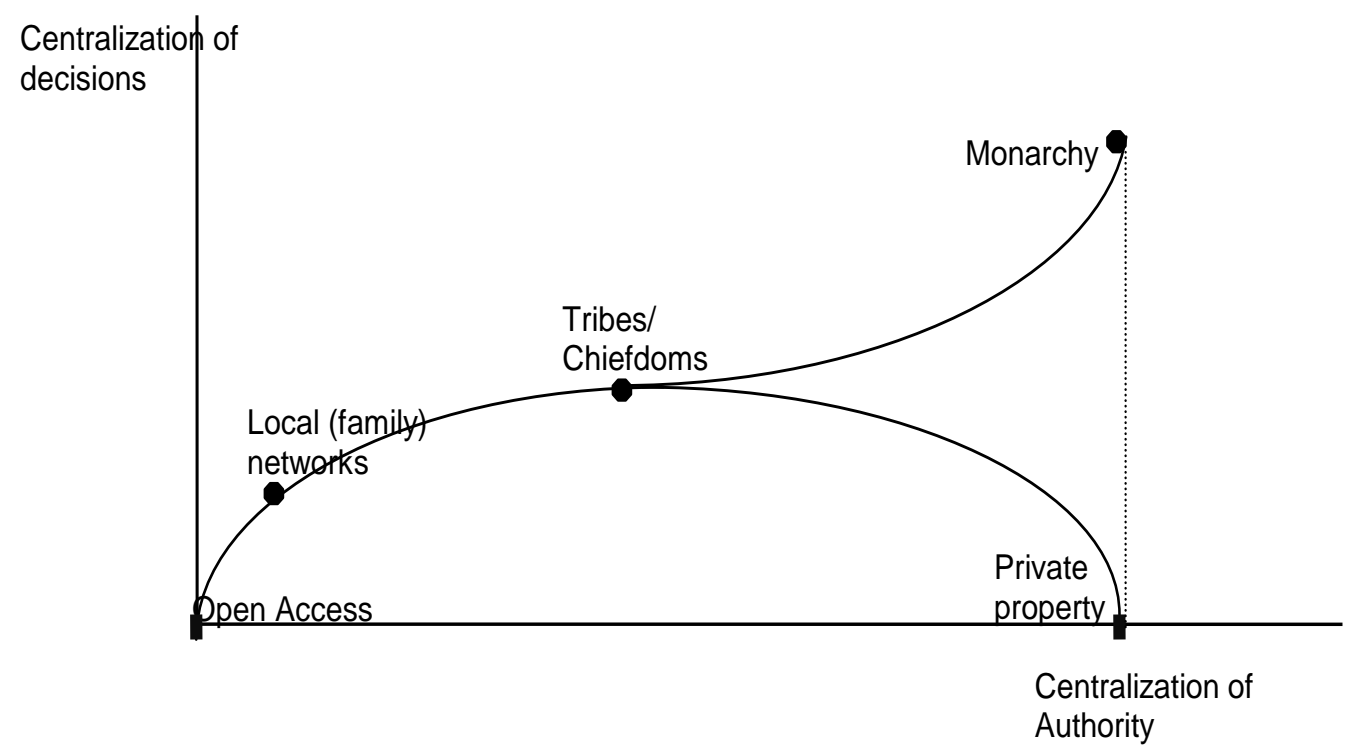

may lead to institutional changes favoring decentralization of decision-making while increasing centralization of authority in the governance of property rights.

Efficient institutional change takes place when the net benefits to doing so are positive. In particular, institutions that manage resources through common property, public property, or private property are perceived as alternative solutions to the open access problem, and comparing these institutions according to the extended Demsetz theory (e.g. Witt, 1987) involves weighing known enforcement costs against the benefits that a particular institution delivers by reducing free-riding. For this we turn to the development and application of our model.

\subsection{The Natural-Capital Theoretical Foundation}

The evolution of property as a function of net benefits of institutional change has been at the heart of New Institutional Economics since its inception. However, the theory is incomplete regarding the nature of agency costs and the lack of capital-theoretic foundations. We hypothesize that property co-evolves with governance, which increases with the intensification and specialization of production; increasing scarcity of land and marine resources leads to more and broader governance and greater resource use restrictions, if enforcement mechanisms are also free to evolve. By drawing on the relatively short time span between settlement and modernization of the Hawaiian economy, we clarify at least one plausible mechanism for this co-evolution. As Hawaii moved from a Neolithic group of small 
isolated villages to a unified kingdom and finally to U.S. territorial status and eventual statehood, old and new institutions, some of which were imposed, overlapped. The experience provides an intriguing opportunity to study how Hawaii's dependency on its resource base, a dependency that shifted with productivity and trade, affected the evolution of decision and authority structures.

In the Coasean paradigm, first-best efficiency, whether achieved through decentralized, centralized, or intermediate institutions, is only a point of departure for comparative institutional analysis. What is needed is a conceptual framework capable of generating propositions and explanations regarding which institution is second-best efficient under what circumstances. ${ }^{4}$ The advocates of private property (Demsetz), public property (Hardin), and communitarianism (Ostrom) all implicitly agree that the relative efficacy of these institutions rests largely on their ability to control the free-rider problem.

As the evolution of economic organization involves managing stocks of natural and produced capital, it must rest on capital-theoretic foundations. In what follows, we exploit resource economics in a generalized and dynamic setting to provide a theory that encompasses the wide spectrum of Hawaiian economic development.

\subsection{An Overview of the Model}

Here we present an intuitive exposition of the model, while the formal model is shown in full in Appendix 1. The main point of the model is to illustrate the interdependency of governance choices, growth and stability in a resource based economy. In particular, we discuss here how changing resource pressures affected Hawaiian institutional development. Like Brander and Taylor (1998) and the literature that their model (henceforth BT model) has spawned (see especially Nagase and Uehara 2011), we use a predator-prey model to illustrate the dependence of the human population on the resource and the susceptibility of the resource to overuse by an expanding population. Many BT models focus on myopic individual decisions in decentralized equilibrium and the effect these have on transitional processes from one period to the next (Nagase and Uehara, 2011). In our model, though, we allow for social planning so that optimization across time periods can occur. One may consider this benevolent optimization by an elite, where the formation of the elite is born as much from the need to solve overharvesting and related common resource problems as it is from exploitation. We do this to better represent hierarchical primitive societies and to focus on governance and enforcement decisions made to curb commons problems. We further transform the BT model by allowing for wealth

4 This use of second-best follows Dixit (1996). He subsumes rent-seeking, corruption, and other elements of political economy in his theory of the $3^{r d}$-best. 
(capital) accumulation that can affect the carrying capacity of the resource and by endogenizing several forms of governance of the resource stock and its use. The dynamics of the wealth accumulation in our model are those of a top-level predator (e.g. a non-laboring elite class) which gains at the expense of present consumption, but funds, through the elite, governance and may in turn increase the resource base's capacity and stock.

In this section, we describe a resource based economic system as a multitrophic economic and ecological system wherein a resource base (prey) sustains a human population (mid-level predator/laborer). The efforts of labor can be consumed by labor, sold externally in trade, or used to generate wealth in support of an elite class (top-level predator). The elite may use governance to maintain unproductive rents (e.g. luxury goods), or to expand the base resource's carrying capacity and/or its catchability $\left.\right|^{5}$ Use of the resource for trade and wealth accumulation reduces the availability of direct sustenance for population growth but, through substitutes (e.g. food imports) and/or technology (e.g. new crops, new harvest tools or techniques) acquired in trade, or investment in the resource base and stock (e.g. irrigation, fish pond construction), may increase average well-being of the population. The distribution of this increase may be distributed widely or captured by elites as unproductive rents (see, e.g. Bardhan and Srinivasan, 1971) or to support an expanded governing class. $\sqrt[6]{6}$

Inasmuch as institutions co-evolve with governance and growth, we highlight elements of the model that can reflect how endogenous and exogenous pressures might affect institutional structures.7] For our purposes, institutional structures include the set of rules under which the society operates and the mechanisms for implementing those rules. This includes e.g. the support of an elite or the branches of government needed to oversee decentralized markets. Intervention into the system can occur through governance of the harvest itself and/or governance and enforcement of the use of the harvested resource. The harvest can be restricted to counter over-

\footnotetext{
5 We concern ourselves with overall growth and dynamics in the system rather than investigating outcomes from agent-based incentives in order to better highlight the various roles of governance at the level of the economic system. We acknowledge that this presents some limitations in being able to directly represent the interests involved in the shift from hierarchical power to decentralization, in particular, but as stated, all institutional structures can be compared in the second-best setting by their ability to move toward the first-best outcome by controlling the free-rider problem.

6 Fishpond construction is discussed at length in this context further below.

7 While institutions can neither easily be modeled as simple continuous functions, nor treated as so instantaneously transformative that one might simply compare institutional settings as separate paradigms, we do not seek, for example, institutionally-defined unique outcomes or game-theoretic understanding of institutional choice as others have investigated recently (Acemoglu et al. 2012; Acemoglu et al. 2011) and we abstract somewhat from the political economy of who plays the role of the social planner (be it a clan leader, ali' $i$, or king, which will differ over time) or how a decentralized economy would operate to achieve the second best outcomes (those including governance costs) described here.
} 
harvesting from open access concerns, at a cost that may be dependent on both resource and human populations and the level of restriction. Then, the shares to trade and wealth can be determined either by an hierarchical elite or by decentralized actions of individuals (the distinction in the model comes through interpretation of the costs of enforcing the share splits).

We break down the model into steps corresponding to three phases of growth in order to illuminate the co-evolution of institutional structures and growth following from an initial setting of colonization of new, unoccupied land.

First, we discuss the base economy as one that is dependent on a biological resource stock that it harvests. As a common resource, the stock is susceptible to overharvest and collapse. This sets up a potential predatorprey dynamic, as in a BT model. In our model, the initial resource level is at carrying capacity while the initial, undiversified human predator population is very low, approximately at its minimum viable population. The small population has an endowment of technology that can expand the resource base even further (e.g. seedlings, domesticated animals), and a set of institutions for governing this technology. Extensive population and resource growth can then flourish while the population uses the initial resource stock to fuel replicative expansion through suitable habitat. Some, but not much, coordination of effort is needed, and small family networks suffice. Minimal governance can be provided internally by productive laborers.

As the extensive growth pushes to the boundaries of the resource base's (now expanded) limitations, without common property management, the resource base will be overexploited and cycles of population growth and decline may follow. Management efforts therefore become more valuable and can generate stability. This increases opportunities for specialization and incentives for intensification or the development of new technologies. With these opportunities and incentives come a rise in stratification that may lead to surplus production. This surplus can be diverted to (productive or unproductive) capital, if enforcement exists to ensure the apportionment of the resource. Management efforts now include monitoring and enforcing a share to funding an elite class that provides this management. 'Production' by the expanding elite shifts from direct resource harvest to management of the resource extraction.

This wealth accumulation, however, also may be used to increase the resource base. If few opportunities for luxury or leisure goods exist, this becomes more likely. Such investment increases the surplus. If the elite govern it for themselves, this further increases governance both of the resource harvest and of the share to the elite, extending the management hierarchy and stratification further. Without governance, costly predator-prey cycles of boom and bust are expected (Brander and Taylor, 1998). The elite, however, can impose a steadier level of resource and population growth through its governance and wealth extraction. 
Without opportunities for trade or technological growth, however, the population is still ultimately limited by the overall sustenance available from the rate of expansion in the resource base. If technological change opportunities are very limited, as they might be on an isolated island chain, then once the human population is fully exploiting the resource base, e.g. when extensive growth opportunities have been exhausted, then further growth will only come from increased specialization and intensification. This will require more control in turn. Intensive growth and capitalization reinforce increasing governance and strengthen hierarchy.

Finally, if technological change is not limited, or if some external shock introduces significant new technologies, then growth from technological change mutes the connection of the human and resource population. Trade works as mechanism for technological change. As such changes become possible, shifts in the relative values of the resource base as used for trade (and technological change), wealth (capital), and consumption occur. These shifts may also alter the returns from governance. In particular, increasing opportunities through trade cannot be best managed through hierarchy for long, unless the opportunities are tied to economies of scale which would benefit from hierarchical management. Decentralization can increase the productivity of the combined resource uses with more flexible structures for turning the new technologies from trade into growth. The direct link between the resource base and the human population is weakened or destroyed, and population and wealth can again expand.

The explicit functions of the costs of governance, which are left in general form here, will differ with the shifts in political economy and we reserve detailed examination of these functional forms for future work. Thus we anticipate that our model is illustrative while still necessarily incomplete.

In the remainder of Section 2, we discuss the model with a focus on governance and enforcement costs and then expand upon the Hawaiian context. In section 3, we discuss some results of the model through the Hawaii case. Also in this section we interpret the model and its parameters under three phases of economic development: extensive growth, intensive growth and capitalization, and external trade - and the pressures that shift conditions from one phase to another - as applied to the Hawaiian case. Here we focus on how changes in relative prices and costs are expected to affect growth and institutional structures. In section 4 we conclude.

\subsection{Model Specifications}

We model the group as striving to maximize the value derivable from their resource base. The dynamics of the resource base, and therefore its value to society, depend on costly decisions over governance of the resource use as well as costly decisions over what shares of the resource should go to each of two non-labor-consumptive uses: external trade and wealth accu- 
mulation. Wealth funds a governing elite that controls the harvest, and/or wealth allows investment that expands the carrying capacity of the resource base. Eventually, when opportunities exist, external trade generates wealth available for consumption of import goods.

The resource harvest is proportional to the human laborer population as determined by effort and assumes a per capita catch that is a function of the resource population. The resource population is determined by the bio-economic conditions affecting biological growth, carrying capacity, and harvest. Harvest reduces the current resource population through pressures for sustenance, wealth accumulation and the elite, and tradable goods via a catchability coefficient. This coefficient represents the ability of the population to convert a resource into harvest (for example the catch rate for fish or the hunting success rate of a pig population). Our model's catchability coefficient has the additional characteristics that governance in the form of harvest restrictions may lower it (decrease catch), and that it may be a function of the elite's capital (through technological advances). This governance of the stock ranges from the strictest possible governance with no harvest to fully open access. Thus increased governance reduces the harvest. If the catchability coefficient is a function of capital, e.g. through promoting innovation in fishhooks or nets, we would in general expect increases in capital investment in harvest technology to increase catchability of the resource population, where we also in general assume that the more abundant the resource, the easier (and cheaper) the harvest. Such increases in the catchability coefficient are likely to result in the need for increased governance of the harvest. Overall, capital investment in expanding the resource base (e.g. irrigation works and/or fishpond construction, as discussed below) is expected to be less costly than capital investment in technological advancement that raises the catchability coefficient.

\subsection{Discussion of Governance and Enforcement Costs}

We expect that the functional form of the agency costs associated with governing catchability and enforcing the distributional shares, as well as their rates of change, vary within institutions as a function of the resource stock, as well as across institutions. Understanding the form of governance of the elite class (e.g. hierarchy vs. investments in constitutions, courts, and other tools of decentralized activity) and the transformation of wealth into growth rather than luxury rents requires understanding of the relationship between institutional structure and governance costs. Here we discuss this in light of the existing literature on harvest governance in order to clarify the intent of using three governance cost structures in the model and to begin to interpret differences among them in terms of their impact on development and institutional change. In particular, we discuss the effect of resource pressures on governance and its costs, and the subsequent effect of 
governance costs on institutional structure.

In the canonical theory (North and Thomas, 1973, and Demsetz, 1967), private property is thought to generate unambiguously higher benefits than open access to resources such as grazing or hunting lands. It is now, however, agreed that, transaction costs aside, the first-best outcomes for resource use may be hypothetically achieved by a variety of institutional forms for property. Ostrom (1990), for one, shows that it is theoretically possible that common property ${ }^{8}$ can achieve efficient allocation, and reviews substantial evidence suggesting that common property regimes were often effective at resource conservation. But the exact meaning of efficiency in these contexts and the nature of the tradeoffs among institutions in achieving it remain vague and/or under-parameterized. This is due primarily to incomplete assessments of the second-best resource outcomes across institutional frameworks.

Without formal modeling, Demsetz (1967) argues that once the efficiency benefits of an institutional change are greater than the enforcement costs, the institutional change will be effected, and private property will be adopted. Here, we add considerable structure to this argument. These governance costs will vary both within institutions and across them, as resource use and relative values for the different purposes of the resource intensify or wane. They are increasing in the resource stock as they enforce against involuntary trades and reduce agency problems of cheating. In Ancient Hawaii, the tabu system was the primary governance mechanism for the harvest.

By allowing governance costs of the harvest and enforcement costs of the shares to trade and wealth accumulation to vary from one another and to vary across institutions, we can be specific about connections between the resource use and costs of governance.

Costs associated with enforcing the share of the resource to the governing elite are functions of the size of the share and the population as well as the institutional structure. They consist mainly of the costs of enforcing physical control of the resource so the rents are not returned to the commoners' (laborers') consumption and informational and transactions costs in using the capital for growth. These include managerial costs of fostering specialization and capturing opportunities for economies of scale. We consider the sum of the governance activities as delineating the (perhaps fluctuating) institutional setting in the context of a human population dependent on a renewable resource base, and we seek to illuminate the dynamic pressures through broad and careful consideration of a variety of governance mechanisms and exogenous shifts in prices, costs, and/or populations.

Others have also attempted to add structure to this matter in ways that enhance our understanding of agency costs regarding decisions over the share of the resource that is not directly used for sustenance. Field (1989)

8 Common property is distinguished from open access by its well-defined rules of access and management. 
suggests an approach to formalizing Demsetz's theory of institutional change. Field begins by noting that economic organization and growth of nonindus-trial economies can be classified into three stages. In the first stage, production is organized by families or small groups of families. In the second stage, these groups are consolidated into larger communal units. In the third stage, production devolves to family farms or other small production units, facilitated by private property. Accordingly, the evolution of property can be indexed by the number of commons. The marginal costs of exclusion are increasing in the number of commons, so that greater resource value is necessary to warrant the expense; complete decentralization under private property is achieved when the number of commons equals the number of firms (or families).

The theory is still incomplete, however. The primary problem is that each institution is implicitly associated with a fixed value of benefits and costs..$^{9}$ A further optimization problem has been suppressed. For the group to manage its resources efficiently it will invest in group contracting and management until the marginal costs of so doing are equal to the marginal reduction in the value of rent dissipation that is achieved thereby. Our model makes these tradeoffs explicit by separating governance of the harvest itself from enforcement of the group's use of the resource, and allowing these costs to vary as the resource base, its relative values in different uses, and human populations vary, as well as governance effort.

Similarly, "exclusion costs" are at best a reduced form function of the number of commons, again avoided by our separation of harvest and other governance costs. The suppressed optimization problem involves increasing exclusion expenditures until marginal value of reduced theft etc. equals marginal cost thereof. Throughout, we have attempted to make these tradeoffs more transparent by endogenizing governance costs, which in effect exploits the key insight of Jensen and Meckling (1976) that monitoring/enforcement costs and residual departures from first-best efficiency are jointly determined. In addition, the potential economies of scale and opportunities for specialization need to be incorporated in assessing that tradeoff, which is why we treat enforcement costs for wealth accumulation and trade independently.

Over the Hawaiian islands' history, social organization went from family

\footnotetext{
9 This is not Field's unique problem but a problem with the theory of institutional change generally. Conventional theories treat different institutions as discreet entities. Field and Anderson-Hill (1975) implicitly index different institutions by a continuous variable. Consider the marginal benefits of dividing the resource among more groups, each of which is responsible for its management. The proposition is that the costs of rent dissipation will go down with increased division. Field properly includes the costs of group contracting in with the costs of rent dissipation. The idea is that group contracting costs will go down in aggregate because of Olson's Law - that "only a separate and 'selective' incentive will stimulate a rational individual in a latent group to act in a group-oriented way." (Olson, 1965) - and that rent-dissipation will go down because there is more accountability with smaller groups and the free rider problem will be better contained.
} 
to hierarchy to more complex and larger hierarchy (vertical and horizontal expansion) to more decentralized private property - just as Field's model might suggest. Transitions were gradual, e.g. with some private property coexisting with hierarchies. Even the great Mahele, often historically billed as a quick transformation in 1848 from hierarchy to private property, took many years to settle, and was incomplete, i.e. it left much land and some marine resources as common property. The degree of transformation was directly linked to the resource base through changes in relative values for the resource in different uses. These shifts in values changed the returns to governance and enforcement costs.

Inasmuch as government has a comparative advantage in some information and enforcement activities, we can extend these total system costs to include those of constitutional governance, e.g. defining and enforcing property rights (Libecap 1978). We consider that these are parts of the costs of governance of trade and capital as appropriate. 10 As with enforcement costs for the share to the governing elite, enforcement costs of the share to trade are also functions of the amount of effort needed to complete the exchanges. We expect that the marginal costs of both enforcing the share to trade and the share to capital are non-increasing in the resource stock. This is because there is a lower level of harvest associated with the higher stock so there are fewer trades to identify and monitor. There may be increased pressure on the governance of the harvest, however, if e.g. sustenance needs of the existing population are not met by the available harvest. Thus, while in general the marginal costs of governing the harvest are expected to be non-increasing in the resource stock, the specific manner in which the combined management of the resource occurs, relative to the human population stock, will affect the rate of change of the governance costs, and possibly even the direction of this change. We expect, however, that these costs will differ in their rates of change across institutions. In particular, we expect that the marginal costs of enforcing the share to trade will grow more slowly under private property than hierarchy, while the fixed costs associated with private property will be larger than those of hierarchy. These fixed costs are important determinants of the constitutional costs in question and the adoption of new institutions in light of changing relative values and costs from resource use and governance.

One significant conceptual weakness of existing property rights theory is its overall lack of capital theoretic foundations, for which our model cor-

${ }^{10}$ In McChesney's (2002) consideration of the famous cattle-trampling of crops, enforcement is not limited to fencing but includes monitoring and enforcement activities by the state. In the efficient solution, governments and private actors each perform those information/enforcement activities in which they have a comparative advantage, much as the Coasean firm chooses to coordinate some production itself and subcontracts other production to outside suppliers. In this view property can arise through private enforcement efforts (e.g. Demsetz's (1967) Native American beaver trappers and Anderson and Hill's (1975) fencing farmers) or through Libecap's (1978) property-defining government. 
rects. As an asset's value increases, it is natural to expect that investments in protecting or enhancing its value will increase over time. Anderson and Hill (1990) have provided a dynamic theory of a one-time investment in enforcement costs, e.g. building a fence, but have not considered the possibility of increasing governance-capital over time. ${ }^{11}$ Our explicit consideration of the dynamics of these governance costs and the share of the resource devoted to the governing elite work to remedy this limitation.

\section{Model Results and Application to Hawaii Case}

Our model acknowledges the dependence of the human population on the resource base as a multi-trophic predator prey model and directly includes governance and enforcement costs. We are able to define three interlinked sustainable dynamic resource paths (Clark and Munro, 1975) that are modified from the first best case to include governance. The detailed functions are in Appendix 1, equations A1.16-18. Recall that in a simple renewable resource case, first-best extraction occurs along a path where the marginal net benefits of the last unit harvested today are just equal to the present value benefits foregone from allowing that unit of the resource to remain in-situ and grow for another period (e.g. Clark, 2005). These costs are therefore also describable as the in-situ benefits. Recall also from the first best case that extraction is along the optimal path when the social discount rate is equal to the growth rate of the resource net of the marginal stock effect. The marginal stock effect shows the sensitivity of the optimal harvest to the variation in the costs of the harvest as the stock changes. In other words the net price is equal to the marginal user cost, which is the decrease in the value of the asset by harvesting the marginal unit (Clark and Munro, 1975). The analogy is useful for interpreting our results. Here, the marginal stock effect includes governance costs. As each path is expressed in relation to the discount rate, the paths therefore may be equated with one another to examine the overall optimal balance of growth in the economy, and the effects of deviating from the paths.

The first path indicates that growth through resource extraction should occur at a rate based on the growth of the resource stock, which may be

\footnotetext{
${ }^{11}$ Even the extended theories of Anderson and Hill (1990) and Lueck (2002) are incomplete, however. First, they analyze only the steady-state institutional costs, wherein rents are fully dissipated under open access, fully captured under private property, and common property regimes lead to resource exploitation that lies between these steady states. Further, both implicitly assume that the enforcement costs of a particular institution are clearly defined. This in turn suppresses the problem of determining, for a particular organizational form, how much and what form of governance is optimal. For the case of common property management, for example, the community must determine the rights and responsibilities of members, and choose an incentive structure as well as its technology of enforcement. Until this governance structure is specified, neither the benefits nor costs can be determined.
} 
enhanced by capital improvements, net a marginal stock effect (Equation A1.16). In the numerator of the marginal stock effect is the per-resource unit contribution to human population derived from the resource, including the effect of governance of the harvest and its costs. The denominator adjusts the marginal stock effect for the value of this contribution, including costs of enforcement and governance. The path will change in direct response to changes in not only the relative value or costs of traded goods and the value or costs of the resource for consumption, but also the costs of governance and enforcement. The inclusion of the governance costs sets it apart from most such optimal resource extraction rules (e.g. the Hotelling rule), and allows us to examine how governance and enforcement can affect the optimal path.

The second path similarly reflects a standard result that the growth of the human laborer population, net of a marginal stock effect, should match the discount rate (Equation A1.17). The marginal stock effect in this case describes the marginal effect on the laborer population from consumption of the changing resource stock, and is a function of governance and enforcement. For example, if the cost of enforcing that a share of the resource go to wealth accumulation increases, then to maintain the given growth rate at the discount rate, not only could the rate of laborer population growth slow or the share to the elite be lowered, but also harvest governance could be increased or the share to trade could be decreased.

The third path also emulates the basic finding that growth should follow capital accumulation with depreciation, net of a marginal stock effect. The marginal stock effect has several components that relate the changes in the human and resource populations on which the capital depends to the changes in value to the society through the technological transformation of the capital to growth (Equation A1.18). Here again the manifold mechanisms for achieving sustainable growth (and the many ways in which such achievements may fail) are apparent.

Of particular interest for our story is the role of intraspecific competition of the laborer population. We see that the effect of the intraspecific competition rate for the laborer population depends on the relative value of the resource for trade or wealth accumulation. If the value not traded, net of the costs of enforcing the share to trade, is greater than the share to wealth multiplied by the governing costs of attaining it, then the effect of increasing intraspecific competition is to decrease the optimal rate of growth of capital in favor of trade, and vice versa. Thus, the optimal response to human crowding varies: when governance costs for both trade and capital are included, if trade is a more profitable option than capital formation, it should be the preferred expansionary path.

Combining information from the three resource paths, we see that over time, the social discount rate should be equal to the growth rate of the resource base, net of a marginal stock effect including governance, which 
should also equal the growth rate of the human population, net of a marginal stock effect including governance. These should all also be equal to the depreciated growth of wealth accumulation, net of a marginal stock effect including governance. All three link the relative tradeoffs from resource consumption for laborers, for trade, and for wealth to a governing elite that may increase investment.

Having briefly described the sustainable paths and the tradeoffs that become more apparent when governance and enforcement costs are directly modeled, we now discuss how population sizes, capital accumulation incentives, trade opportunities, and governance affect these modified extraction rules, and investigate what can be said about the effect of governance and its costs on optimal paths for growth in the context of Hawaiian development from Colonization forward.

Overall, the Hawaii case offers an opportunity to witness a resource dependent economy that did achieve high, sustainable levels of output and growth over at least 600 years. Harvest governance structures appear to have been very flexible and key to this success.

\subsection{Phase 1: Extensive Growth}

Figure 3 shows the dynamic model reduced to a simple case where extensive growth is possible, but bounded by the limits of the resource base. In our model, extensive growth is identified as increases in social welfare that occur without the feedback linkages from a governing elite (capital) increasing the resource base and without increases in the unit costs of harvest. In other words, the system can replicate itself with constant marginal costs through expansion into new land areas. This can happen when harvests from the resource base do not overexploit the resource, which can occur when resource pressures are low and/or when governance of the harvest is high, if governance could occur without a governing elite. The increases in social welfare may be captured as rents or come through population growth, but if they are mainly captured as rents and there is no population growth, then extensive growth cannot continue long as there will be insufficient population to conduct the growing harvest. The elite must pay for itself. Further, extensive growth is more likely if intraspecific competition is low, in that the population may expand without significant conflict. The costs of enforcing significant shares of the resource harvest to non-reproducing wealth accumulation will be high, especially compared to the benefits when there is little resource scarcity. As such, decision structures may be fairly flat and authority rather decentralized.

In Hawaii, this is clearly the case in the colonization and development eras; as 'ohana (family) networks provide both the decision-making and the authority at the level of the extended family, or tribe. Colonization and development are combined as a period of extensive growth as Polynesians 
Figure 3 - Extensive Growth
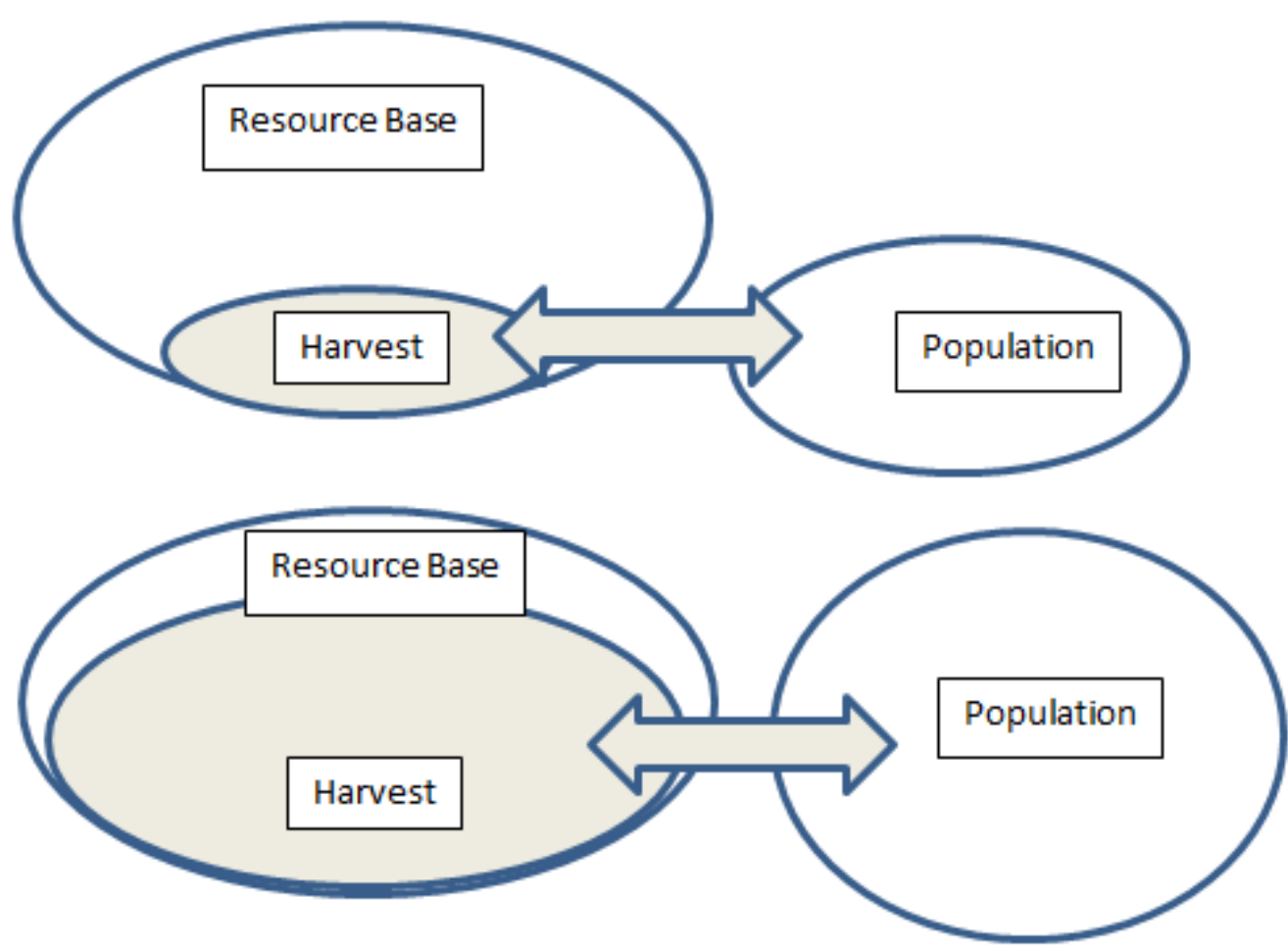

Little management is necessary at low initial population levels and high resource levels. Population growth leads to higher harvest levels and a depleted resource base. Eventually, without coordinated management, population growth may initiate cycles of growth and demise as the harvest level increases relative to the resource base and overexploitation occurs. Optimization by the group can prevent these cycles.

arrive and sparsely settle coastal areas, moving slowly upland and then replicating across approximately 30 valleys during expansion (Hommon, 2013). Negative Malthusian effects on income are limited as population growth is easily supported by the marine resource base. There may be positive (Boserupian) forces from increased population growth on per capita income through specialization and the development of the ahupua' $a$ system, and other external economies of specialization or learning-by-doing.

There is little expected benefit from capital accumulation as value to an elite class, and little archaeological evidence that there was any. Initially small populations consisted of perhaps 100 people in an extended family or 'ohana (Kirch, 1996). Governance for some time after the Polynesians arrived in Hawaii (roughly 400 A.D or later) developed under a community management ('ohana) system wherein the patriarchs of each extended family determined production and enforcement. With the introduction of new agricultural products (e.g., pigs, taro) and the slow subsequent transformation of the most fertile valleys (wet, windward areas) adjacent to superior fishing grounds, the first, extremely low, populations grew into populated communities consisting of about 90 households in an average ahupua' $a$ (Hommon, 
2013). Marine and terrestrial resource pressures were low, $\sqrt{12}$ and though societal institutions to govern resource scarcity, particularly the kapu (taboo) system, had traveled to Hawaii with the earliest Polynesian settlements, implementation and enforcement were low (Kirch, 1996). Some human labor was likely directed from abundant marine resource harvest to land resource cultivation, but these increases in the resource base would have come at a low cost in the absence of overall scarcity. There is considerable evidence of time spent in the development and enjoyment of leisure activities - the most famous being surfing (Kuykendall, 1938; Finney and Houston, 1996).

From these beginnings, we see continuous evidence of increasing intensification of production both on land and at sea - Boserupian growth (Roumasset, 2008). Technology becomes standardized, evidence of intermediate goods produced by a rising class of specialized adze-makers and fishhook producers (Kirch, 1985, p. 184). This would correspond to increases in technology in the model, though these increases would not transmit widely through the system here, as there is little elite wealth accumulation or stratification during the extensive growth period. Further, there is little or no need for expansion of the resource base, since the new Hawaiian population is at first lower than an equilibrium population determined by optimal use of the marine resource. Any capital accumulation is therefore considered to be generated because of net value to an elite, reflected in the value of capital, which would be low due to the lack of available status goods, and the cost of enforcing the share of the resources for the elite (capital), which would be high as discussed. If there are few opportunities for external trade, so that the value of trade is essentially zero, then the share to trade will be zero, regardless of the costs of enforcing a share to trade. Note that there is some interchangeability between value derived to the elite from capital and external trade in that these are shares of resource that are siphoned off from population growth into non-reproducing profit.

As populations grew and became more permanent in the Developmental era and into the expansion era, governance by family eventually extended to governance of the entire ahupua' $a$ valley, under a single chief or ali' $i$. During the Expansion Period (1100-1650 AD) population estimates for the islands increase to several hundred thousand people, with some estimates reaching as high as 800,000 people (Kirch, 1985; Kameeleihiwa, 1992).

\footnotetext{
${ }^{12}$ It is clear from bone pile analyses that pig and dog populations were growing rapidly over the time period and increasingly supplementing the fish protein collected from the sea, and resources were increasing as transplanted food species took hold in the new environment.
} 


\subsection{Transition from Extensive Growth to Intensive Growth and Capitalization}

With extensive growth, it may indeed be the case that open access, where harvest governance is not undertaken, is efficient. That can occur when the costs of any governance are greater than or equal to the growth in value of the resource for population growth, or the marginal benefit of the governance foregone. The optimal resource population will be an increasing function of the value of the resource to the population, the death rate, and the level of intraspecific competition, and a decreasing function of the intrinsic growth rate of the human population, the catchability coefficient, governance costs, and the rate of change in governance costs as governance changes. As extensive growth continues to expand population and to encompass the full productive capacity of the resource base, the death rate and and intraspecific competition are expected to increase. In order, then, to increase the resource population to accommodate this growth, increasing governance is needed.

Increasing governance at a constant marginal cost of governance will increase the optimal population, as one would expect. The effect of increased governance if marginal costs of governance vary is less clear, however. If we assume that governance costs are increasing in governance (or in the human laborer population), as would be expected within an institutional structure, then the increasing costs have a dampening effect on the governance's usefulness in increasing the resource population. If governance costs could be lowered by changing institutions, then the optimal resource base can grow. Changing institutions, however, is expected to have considerable fixed costs. For the transition to be advantageous, the returns from the increased resource base must cover these fixed costs. Thus overall it will be efficient to use a governance institution with higher marginal costs than are available for the scale of the economy under another institutional structure until the point where the value of the increased conservation covers the fixed costs of the transitions.

If the resource base is being used at capacity and there is no possibility to augment the resource base or the effectiveness of harvest in sustaining either human laborer population or elite (capital) growth, then change must work through intraspecific human competition and/or the death rate. If either or both of these increase, they reduce the human population and in turn reduce some of the pressure on the resource population. This will be visible in fighting, disease, and other stressors to the population, including moves into marginal lands that require higher labor inputs, all of which occur in Hawaii starting in in the middle of the 2nd millennium.

The decision-makers in the system (be they hierarchical or the framers of a decentralized playing field) can alleviate this effect on the population either by reducing the population through e.g. warfare, or through enhance- 
ment of the resource base through the capital stock/management of the wealth-funded elite. Thus the larger the ability to transform capital into increased resource base, including the costs of attaining that capital, the more successful the economic system can be at growing through economic intensification and capitalization vs. stagnating and devolving through warfare. Even with opportunities for technological change being extremely limited, as they were in Hawaii, equivalent effects may, for a time, be achieved through increasing the resource base.

In Hawaii, the acceleration of population growth, particularly from 12001650, was followed by the intensification and transformation of food production, including capitalization. Wet, windward valleys were irrigated, and population expansion covered virtually all such valleys by 1450 AD, when soil analyses show significant dryland agriculture developments beginning. The increase in population that had been accommodated by resource abundance and good conditions for extensive growth needed new ways to sustain itself, and dryland agriculture provided it. The shift appears to have evolved in two different ways. First there was an expansion to new areas, then the intensification of previously established areas for higher yields (Ladefoged and Graves, 2008). The simplest expansions had no accompanying infrastructure development. Other expansions involved significant rock terracing and other infrastructural developments. Intensification on existing plots included both capital improvements and labor intensive activities including mulching and weeding (Ladefoged and Graves, 2008). These analyses indicate that virtually all arable lands were brought under cultivation by 1650, and that at this time population growth slowed significantly and may have even reversed (Kirch et al. 2004).

This stagnation does not spiral into a collapse of the entire system in large part due to the success of the intertwined governance structures outlined above. An elite did form; Hommon (2013) estimates that the governing hereditary aristocracy consisted of somewhere between 1-2\% of the total population, sustained by the efforts of the commoner class. The Polynesian hierarchical governance structure provided the tools integral to achieving and managing a steady state. McClenachan and Kittinger (2013) show that after increasing production considerably over the initial period of growth in Hawaii, the islanders were able to sustain annual catches from reef environments exceeding 12 metric tons per square kilometer of reef annually beginning around 1450 and continuing for over 350 years at an essentially steady state (see Figure 1 in McClenachan and Kittinger (2013)), whereas most coastal reef fisheries globally that harvest over 5 metric tons per sq. $\mathrm{km}$./year currently show signs of unsustainable overexploitation. There is some evidence that certain high-value species suffered from overexploitation across the span of time, but overall reef productivity proved sustainable due to governance. 


\section{Figure 4 - Intensive Growth and Capitalization/Elite-Formation}

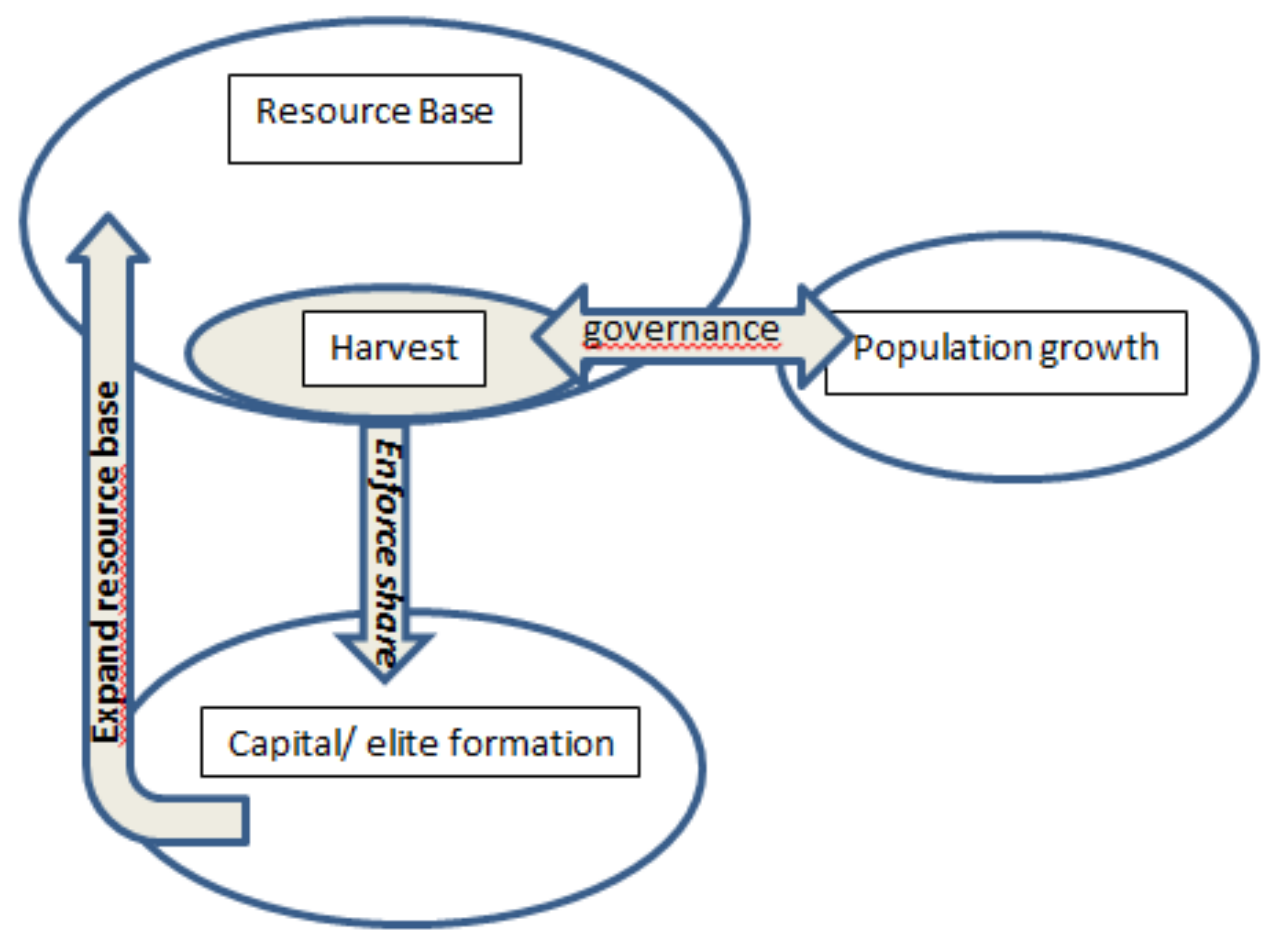

The need to govern the harvest initiates increased stratification. Further increased governance allows for surplus production. Some of this may become productive capital that increases the resource base. The rest funds the elite, which provides governance and strengthens stratification.

\subsection{Phase 2: Intensive Growth and Capitalization (Without Trade)}

As the human population expands the limitations of the resource and its dependent human population face significant challenges for further growth. The formation of an elite class and capital investment may counter these challenges by providing management to reduce the commons problem, to organize labor for capital projects that increase the resource base, and/or to provide management for specialization opportunities. Figure 4 illustrates the model when capital accumulation is possible. We continue to limit opportunities for trade so that the value of trade is zero and no resources are diverted for trade. Now, however, capital accumulation has a positive value as investment into expanding the resource's carrying capacity and in providing governance of the harvest through an elite class. We investigate how the incentive to set aside a portion of today's consumption affects the resource base and human population in relation to the case of extensive growth.

In addition to harvest governance, capital accumulation can affect the optimal resource population. Adding capital accumulation to the options works to decrease the optimal resource population (increase the harvests), 
as one would expect. The extent of this decrease depends not only on the share of the resource going to wealth accumulation/direct support of the elite, but also on the enforcement costs of attaining that share and the rate at which those costs vary as the share increases and the human laborer population is reduced from lower consumption. The higher these rates, the lower the optimal resource population will become, as the share to wealth becomes more 'expensive.'

Once wealth accumulation is under way, as the value of capital increases or the technological ability to transform the wealth into resource growth (directly or through management) increases, ceteris paribus, the optimal resource population will become higher. Increasing the share to capital (at constant marginal cost) continues to result in a lower optimal resource population. Increases in the marginal cost also reduce the lower optimal resource population.

Along the optimal resource extraction path, the present value of a unit of the resource converted to capital will be equal to its marginal opportunity costs, which are the current value of a unit portion of consumption plus a combined term reflecting the direct and indirect costs of enforcement of the share. ${ }^{13}$ Thus increases in the value of the wealth, either for the elite or investment, can sustain higher costs of enforcement. Changes in the relative values of the resource for laborer consumption or elite wealth (capital) will affect the split in expected ways; increases in the relative value as capital will increase the share for capital and vice versa. The effect of changes in the effectiveness of the conversion of capital into an expanded resource base is as expected, as is the effect of changes in the intrinsic rate of growth of the resource. As either increases, the optimal share to capital decreases, as it takes less of the resource to expand the base, and more of the resource is available for consumption.

We can also glean the effect of harvest governance (with constant marginal costs) on the optimal split to funding the elite (capital). If harvest governance increases, the optimal share to the elite should decrease, ceteris paribus. As we stated earlier that increasing governance should increase the optimal resource population, this contrast suggests that increasing harvest governance will benefit current consumption at the expense of capital growth. This is related to the relationship between human laborer population and the optimal share to the elite. If human laborer population increases, then the optimal share to the elite will increase if harvest governance is sufficiently lax that the population can continue to sustain itself in spite of the increasing share to the elite (capital).

\footnotetext{
${ }^{13}$ Note that the cost of harvesting the resource itself need not be part of the tradeoff here as it must be paid regardless of the use of the resource.
} 


\subsubsection{Hawaiian Intensive Growth and Capitalization (Without External Trade)}

Continuing along the development path of Hawaii, we follow how the islands sought increasing resource capacity from capitalization both on land and at sea, and how this was intertwined with both governance of the harvest and enforcement of the share to capital. A chief allocated land and labor within one of many wet, windward valleys to their uses and began to take advantage of the top-down power to achieve economies of scale and increased production intensity through specialization, eventually building large-scale irrigation projects for taro cultivation and fish ponds in particular. After approximately $1450 \mathrm{AD}$, dryland agriculture techniques evolved that allow expansion into more marginal lands (Kirch et al. 2004). The sweet potato was the main dryland crop. These techniques were more labor intensive and had smaller rents (Vitousek et al. 2004). Field et al. (2011) have linked household expansion to agricultural intensification through the frequency of evidence on residual features and markers of dryland agriculture. These links identify exponential expansion between 1400 and 1800 AD and corroborate earlier timelines on agricultural development (Ladefoged and Graves, 2008). Increasing management is linked to extractable surpluses for the period after 1100 (Field et al. 2011).

Further, Vitousek et al. (2004) argue that the dryland techniques used on Maui and Hawaii (the younger, larger islands) were not well suited to the older islands of Kauai, Oahu and Molokai due to soil inadequacies from weathering. The wet, irrigated valleys of the older islands are also closer in proximity to their fishing grounds. The most intensely developed dryland locations were also closest to fishing grounds (Ladefoged et al. 1996), and as such were less risky agricultural developments.

Enforcement also accelerated, particularly at the end of the period and on the more marginal lands. The archaeological record shows evidence of this increased temple-building, consolidated control, and expansion of territory on both Maui and Hawaii (primarily dryland) from 1570 to 1630 AD (Kirch, 2005). Within this growing hierarchy, decision-making and authoritative duties came to be addressed by different parties acting for the chiefs. "Low-level" konohiki resource managers ${ }^{14}$ developed increasingly sophisticated irrigation ${ }^{15}$ and communal fishing techniques. Kinship networks give way to specialized skills in fishing and farming, managed by the konohiki. Without external trade, hierarchical stratification increased, as did efforts at resource extraction for the benefit of the ali $i$. The commoners produced for the konohiki, who controlled the water supply, determined the land alloca-

\footnotetext{
${ }^{14}$ For illustration of Hawaiian hierarchy, see Kirch 1985.

${ }^{15}$ In particular, increased use of Type III irrigation systems, consisting of an irrigation canal running along the periphery of the field complex, allowing more sophisticated control of water distribution than was used in earlier Type II systems, where small groups of fields were watered by a single ditch that fed directly into the uppermost field.
} 
tions for the commoners, determined fishing rights, and allocated ahupua'a resources for production, especially labor for communal projects. The konohiki's duty to the ali' $i$ was to meet an expected production goal to be presented during the makahiki festival ${ }^{16}$ at which time the ali' $i$ divided the tribute amongst his supporters in the chiefly class, including the konohiki. The konohiki became the enforcers of the share to the elite (capital), which was set by the higher ali $i$. Increased governance came from the parallel development of a large priesthood and increasing use of the kapu (tabu) to restrict resource use and population. In our terms, the priesthood controlled governance of the harvest. This structure supported an increasingly stratified society.

This stratification appears to have steepened more rapidly on marginal lands than on lands that produced large surpluses easily (Kirch et al. 2004, Vitousek et al. 2004). Without additional trade opportunities to increase economic growth, the proto-historic period also experiences increased warfare over increasingly scarce resources, mainly initiated by chiefs controlling these marginal lands. As hierarchy grows and we identify divisions in those responsible for governance, we see that coordinated behavior in the system is more difficult.

Once the best land is brought under cultivation, production expands according to the increasingly intensive Ricardian gradient. As returns diminish, specialization and intensification may evolve to increase yields from an existing resource base through land-saving technical change. The use of labor-saving tools begins along with modest capital accumulation. Intensive growth is further promoted by specialization, as witnessed by standardization of production tools and techniques. Increasingly centralized decision-making facilitates horizontal specialization by task. Vertical specialization increases. The ali $i$ (chiefs) are not replaced; they are merely consolidated by adding vertical layers. Governance expenditures increase accordingly as warranted by the gains from horizontal specialization. In the case of Hawaii, as population grew and spread from the coast inland, intensification generated stronger links between 'ohana and the hierarchical authority and decision-making increased together, taking advantage of increasing specialization in agricultural and fisheries inputs and outputs. ${ }^{17}$

${ }^{16}$ Captain Cook's arrival to Hawaii in 1778 occurred at the time of this festival, and westernized descriptions of the activities have portrayed the primitive economy as having 'well established markets' amongst other Western concepts foreign to the Hawaiian culture at the time.

${ }^{17}$ Evidence from joint archaeological and soil scientist work (Vitousek et al. 2004; Kirch et al. 2004) on the intensification of dryland agriculture on Maui and Hawaii versus the less labor-intensive, higher-surplus irrigated wetland agriculture on Kauai and Oahu may explain why the more aggressive and expansive chiefdoms grew from Maui and Hawaii, and that final unification came under a chief from Hawaii, rather than the older islands of the archipelago. These chiefs were motivated to increase their authority and expand their territory because the rents they could extract from the marginal lands they controlled were lower than those extracted by the chiefs irrigated wetlands. 


\subsubsection{Fishpond Development: Capital Accumulation and Governance}

One key mechanism for resource expansion was the fishpond. Hawaiian fishponds evolved into true aquaculture, $\sqrt{18}$ a unique Hawaiian development amongst Polynesian cultures, to increase productivity and as a direct example of expanding the carrying capacity of the resource through enforced investment in the elite. Fish pond management indicates intensified governance as well. Strict limited access to the ponds controlled rent dissipation, and governance measures increased accordingly. 30\% of ahupua'a had associated fishponds (ponds never crossed ahupua' $a$ borders), and the ponds' total area of about 6650 acres would have produced somewhere between 1.75 million and 2 million pounds of fish per year - about 6 to 9 pounds per person per annum at the time of Western contact (Kikuchi, 1976; Hommon, 1975) ${ }^{19}$ With little trading between ahupua' $a$, and the ability of the ali' $i$ to reserve the catch for themselves, fishponds produced considerably greater sustenance for the higher levels of the social hierarchy with little direct benefit to the commoners, though indirect benefits stemmed both from reduced fishing pressure on the coastal fisheries and from the increased fish stock overall.

The hierarchical ahupua'a system allowed the capture of the economies of scale necessary to develop these fishponds while the complementary kapu system provided the mechanism by which efficient harvesting could be enforced. Inasmuch as the ali' $i$ captured the rents, this exemplifies a case in which the primary action group (Davis and North, 1971) undertakes the institutional innovation in question.

This system of control evolved into an extensive hierarchy during the Expansion era and eventually crystallized during the proto-historic period (1650-1785), at the height of the islands' population, exhibiting a much higher degree of social hierarchy, specialization, and governance structure than in other parts of Polynesia (Abbott, 1992; Handy and Handy, 1991).

From records of oral genealogical history, we know that populations must have been driven to create ponds as soon as there was sufficient labor available to do so, if appropriate environmental conditions existed. There are 6 known fishponds constructed on Oahu and Kauai before the $13^{\text {th }}$ Century (Kikuchi, 1973). Also at this time communities begin to develop in the drier, leeward valleys, suggesting population expansion and resource pressures. The primary growth in fishponds is attributed to the $16^{\text {th }}$ Century (Kikuchi, 1973), as is the growth in population. By the $18^{\text {th }}$ Century, repairs to existing ponds may have been as important as new construction. The last ponds were constructed at the beginning of the $19^{\text {th }}$ Century, as Western contact and the resulting population decreases changed the social

\footnotetext{
18 True aquaculture means that fish are bred and nourished in captivity; other Polynesian fishponds were holding pens fed by ocean tides.

${ }^{19}$ Population in the islands has been conservatively estimated at 200,000-225,000 in 1778, at contact.
} 
structure and manpower of the islands. As the hierarchical authority in Hawaii strengthened, these and other large capital projects, particularly irrigation projects to increase taro production, were undertaken, with rents accumulating mainly to the high chiefs. More profitable opportunities for the ali $i$ also developed in trade for other resources, particularly sandalwood, to which we return in the discussion of trade.

\subsubsection{Transition to a Trade-based Economy}

As demand increases, whether due to increased population pressure or increased opportunities for rent-seeking, resource productivity may be enhanced through capitalization (including elite formation) that captures economies of scale, so that the choice and costs of how much of the resource to devote to capital development and the technical capabilities captured by technology under different institutional arrangements continue in importance, even if the direct connection to population is reduced. Infrastructure and other capital-deepening/governance stratifying enterprises may increase the productivity of existing resources (e.g. the effect of irrigation on land and water productivity) and/or increase resource flows from existing stocks. Increasingly centralized authority and decision-making will together increase the ability to capture economies of scale.

Hierarchy lingered past Western contact and its institutions for private property, culminating in the Hawaiian kingdom formed under Kamehameha I in 1805. Most local resources experienced dramatic changes in value and governance needs after Western Contact, however. While rent extraction by the Hawaiian chiefs was expected and accepted as the way of life, the hierarchical authority included a mechanism for transferring these rents every generation in order to maintain consolidated support for the ali' $i$ nui, or head chief. This mechanism, the mahele, was a redistribution of rights from top to bottom that occurred with every change of leadership. With consolidation into the Hawaiian kingdom under King Kamehameha I after Western Contact, rent extraction opportunities increased rapidly. Kamehameha I, however, was a conservationist, and under his reign, three major fishpond projects were undertaken, and sandalwood trading with Westerners was carefully managed. He ordered that yams, less preferred for local consumption but attractive for the shipping trade due to their longevity, be planted in Honolulu to increase the resources available for trade (Ladefoged, 1993). This early decision foreshadows the shift in resources away from consumption and toward trade.

Enforcement costs of the consolidated hierarchy increased under his successor, Liholiho. Unable to bring about a mahele, the chiefs gained power to extract greater rents of their own, with greater competitive pressures among them, and sandalwood resources quickly dwindled (LaCroix and Roumasset 1984). The introduction of new religious institutions (Christianity in particular) and the apparent impotence of the Hawaiian gods in protecting the 
population from Western diseases rendered the kapu system less effective and the system was officially abandoned in 1819 (Kame'eleihiwa, 1992, p 140ff). Sandalwood was depleted by 1850, leaving not only a void in tradable goods, but also considerable environmental degradation to watersheds. Thus the greater scarcity of extractable resources increased the benefits of conservation just as the hierarchical institution designed to protect them failed due to the increased costs of governance.

The subsequent transition to private property, frequently portrayed as an overnight coup defined as the GreatMahele of 1848, was neither instantaneous nor complete. Neither fully-formed fences nor production and enforcement systems materialized overnight, though the relative cost of moving to private property, despite the large initial fixed costs of the Great $\mathrm{Ma}$ hele and of establishing a series of constitutions, had become efficient. The scope and breadth of central government authority increased; these constitutions established a cabinet, a civil service, and an independent judiciary by 1847. Through this expensive investment government lowered per-unit costs of providing governance and ensured a higher level would be provided. At the same time, the move lowered informational costs by enabling decentralized decision-making through private property.

\subsection{Phase 3: Trade and its Introduction in Hawaii}

The incorporation of trade into the model expands the options for resource use in ways that are similar to capital accumulation; the share that should go to trade is increasing in the relative value of trade and decreasing in cost of trade to the human population, for example. In fact, if there is no cost to the human population in terms of lost consumption (because it is replaced with traded goods) then the harvest will go to trade rather than consumption.

Increases in harvest governance effort, however, unlike the case of capital accumulation, are now seen to increase the share to trade, ceteris paribus. Both of these findings work to explain the importance of trade in continued economic development, if the direct relationship between the resource and the human population can be reduced. This cannot happen with capital alone, if there are no materials available for technological development.

A further distinction that the separation of enforcement issues in capital formation and trade allows that is highlighted by our model is that trade can significantly weaken the dependent link between the resource base and human population growth. The model illustrates this through the tradeoff between the resource used in trade and the resource used for consumption and internal capital developments. Since the traded goods will now determine survival and standards of living, control of the resource for trade and the distribution of returns from trade are more important factors in support for the institutional structure of the economy than without trade. We con- 
sider this a major factor in the drive for decentralized property rights.

After Western Contact the rate of depopulation increased dramatically; the native population decreased, perhaps by $90 \%$ in a generation, rapidly deflating the pressures that drove specialization, intensification, and the growth of governance beforehand. New products were introduced driving fundamental economic shifts and reducing the effectiveness of ahupua'a management in meeting society's needs. The kapu governance system was soon in tatters, raising the enforcement costs of hierarchy.

The population decline after Western contact was not accompanied by a direct reduction in resource pressures, however. Resource pressure from population growth alone is therefore insufficient to explain increases in governance and intensification. Instead, relative prices for resources began to shift; for example, with respect to marine resources, benefits from coastal fisheries for local demands were reduced while benefits from ocean fisheries for trade expanded. Sandalwood, ship provisioning, and even a few years of market dominance supplying California with potatoes at the start of the 1849 gold rush, all brought shifts in relative values for the resource base (Ladefoged, 1993). Institutions shifted accordingly, and governance efforts did not abate, as the new judicial system and constitutional monarchy placed control over public goods, particularly education, in the hands of a representative legislature (Daws, 1974, p. 107). Over time this legislature imposed more stringent rights and governance on the increasingly valuable ocean fisheries and a return to less stringent and more local enforcement in less valuable coastal fisheries.

While our model cannot predict such shocks as the sudden introduction of myriad technological improvements and shifts in resource values, it does illustrate how the economy responds. Our optimal extraction paths show the interconnectedness of these exogenous shocks to value shift in such a way that we can determine what must happen when the relative value for trade increases compared to consumption, either from a reduced population or from a new desire for different goods not available from the resource base (or both), while simultaneously the costs of enforcing the shares to trade and capital, as well as the resource harvest governance, are increasing within the existing institutional structure. This increase in desirability of trade, with failing institutions to govern it, must be accompanied by an increased discounting of the future or a reduction in the population to maintain the resource base. Thus had not the population declined exogenously (through disease in particular) the old system of resource dependence would not have been in any case sustainable with trade. The separation of the population dependence on the resource and the value from trade, however, that one can visualize through a significant increase in the death rate accompanying these changes, reduces the pressure of many of the linkages between resource governance and population growth. We argue that this allows increased scope for institutional change that focuses more on the 
efficient deliverance of the resource base to external trade than it does to population growth.

Though the big picture of institutional change in Hawaii is one of increasing resource pressure accompanied by increasing governance and decentralization of authority, governance may also vary over space and time according to the present value of the remaining resource stock. During the $19^{\text {th }}$ Century evolution of property rights, the konohiki maintained governance rights over the less trade-valuable coastal, common-property fisheries as a less costly governance mechanism available within the existing Hawaiian institutions. Private decision-making within the new property rights system for fisheries continued to balance enforcement costs against benefits as well. Konohiki sought to incur the costs of fishery registration when the asset was more valuable, leaving less valuable assets to open access. Furthermore, as time decreased the value of all coastal fisheries due to native population reduction, increasing international trade and the greater availability of preferred substitutes, governance over all coastal fisheries decreased. Because they nicely illustrate the differing applications of governance and the connection with institutional change, we discuss details of these fisheries here.

\subsection{Fluctuating Institutional Arrangements and Governance: Fisheries}

The ahupua' $a$ extended into the sea, and property rights were also redefined and extended in coastal fisheries. Fishing rights remained tied to the management of the land, and remained in the hands of the konohiki, ali' $i$ and the king, with intent of balancing stewardship for the people with private goals. While the fisheries were still common property, enforcement costs and benefits in coastal fisheries controlled directly by konohiki differed from those of the government controlled, open water fisheries, and the coastal, konohiki-managed fisheries. While government lands and their appurtenant fisheries quickly were opened to the public, the konohiki retained their rights to private use throughout the $19^{\text {th }}$ century.

The konohiki (acting for the ali'i) could regulate fishing by monopoly reservation of a particular species and by seasonal restrictions, as this governance was no longer in the hands of the discredited priesthood. He could collect in rents $1 / 3$ of the harvests of open access fishes, for the benefit of the ahupua'a (Khil, 1978, p 10). The rights belonged to the job of konohiki, not the man, and were not transferable, with the intent of maintaining incentives for stewardship. The king also had the ability to set restrictions on non-transient shoal fishes and transient shoal fishes in the Main Hawaiian Islands. He was entitled to $2 / 3$ of all harvests, for the benefit of the government (Khil, 1978, p. 11).

Throughout the 1840s, the Great Mahele and the changing constitutional 
rights slowly made more explicit the powers of the konohiki and the king and their portions of the take changed. In 1841, the king's take was reduced to $50 \%$, and in 1845 , the konohiki was given rights over the sea extending one mile from the beach at low water. The catch was to be shared evenly with the tenants.

In 1848, Hawaiian property rights received their greatest institutional change under the Great Mahele. Under increasing pressure from the growing Caucasian population, the land was permanently divided amongst the king (state), the ali' $i$ and konohiki (ahupua'a) and the commoners, paving the way for transferable rights to land and sea. It is at this time that the role of the konohiki seems to have changed from steward to owner ${ }^{20}$,

The monarch's fisheries moved towards open access ${ }^{21}$ while many of the konohiki, where governance provided valuable returns for native consumption but not necessarily for trade, adopted stricter enforcement policies. In 1858 , tenants regained some legal ground in piscary rights with a court ruling that stated the konohiki rights were subject to the tenant's rights, where tenants included all residents of the land (Khil, 1978).

The opening of state fisheries to the general public was explicitly an act to reduce enforcement costs on a low productivity resource. The new law, enacted in 1850, read in part:

Whereas the fish belonging to the government are productive of little revenue ${ }^{22}$; and whereas the piscary rights of the government managed by the fishing agents are a source of trouble and oppression to the people ... all fish belonging to or especially set apart for the government shall belong to and be the common property of all the people equally ... All fishing grounds pertaining to any government land, or otherwise belonging to the government, excepting only ponds, shall be, and are hereby, forever granted to the people for the free and equal use of all persons... (in Khil, 1978, p. 13)

This law increased pressure on the fisheries and resulted in the slow subsequent introduction of increased governance in the forms of gear restrictions, size restrictions, and seasonal restrictions. ${ }^{23}$

${ }^{20}$ Though the Great Mahele ostensibly divided land in equal shares between the royalty, the chiefs and the commoners through the agency of the konohiki, the actual process of attaining title to fee simple property was complex, and in particular, required a commutation fee that resulted in a large portion of the chiefs' lands being returned to the state in payment. The commoners' inability as a group to acquire much fee simple property stemmed from hurdles that included paying for land surveys and unfamiliarity with the system. Fewer than 8421 parcels, averaging 3 acres in size, were in the end awarded to commoners, accounting for 28,658 acres of land, or less than $1 \%$ of Hawaii's land area (Kame'eleihiwa, 1992, p. 294). The main beneficiaries of the Great Mahele appear to have been Westerners who could now obtain fee simple land.

${ }^{21}$ This is not to say that informal, non-governmental limitations of fishing rights did not exist.

${ }^{22}$ The use of the term revenue highlights the new importance of markets.

${ }^{23}$ In 1850, use of fish poisons was made a misdemeanor offense. In 1872, use of explosives 
After annexation in 1898, and shortly thereafter the passage of the federal Organic Act in 1900, the konohiki fisheries came into conflict with federal law. The Organic act repealed all exclusive rights, but left a two-year window during which holders of exclusive rights could register and adjudicate their private claim. Any successful private claims could be condemned for public use, however, with allegedly proper compensation. Of the more than 400 private fisheries at annexation, only 107 registered claims were made within the mandated window. More than half were on Oahu, with its greater population, closer proximity to the courts, and growing reliance on markets, factors which lowered the transactions costs associated with enforcement and increased the net benefits of conservation activities.

The registered fisheries also held greater assessed market value on average. At least two attempts were made to value the konohiki fisheries, in part for use in condemnations. ${ }^{24}$ The first, in 1939, described 349 konohiki fisheries, 101 of which were registered. Table 1 summarizes their findings by island. The first column shows the number of fisheries. The second and third columns show the total and average values for the island's fisheries respectively. Note that Kauai and Oahu have much higher than average returns per fishery, and that these two islands also have much higher percentages of fisheries registrations, as shown in column 4 . Column 5 shows the percentage of the total estimated value (Column 2) that is attributed to the registered fisheries. Registered fisheries on Kauai, Oahu, with considerably higher average returns per fishery (Column 3), and Molokai, with low population and little immigration, all generated greater returns than the average value for the respective islands (comparing columns 4 and 5). Hawaii has the lowest level of registration; its fisheries have low average value as well ${ }^{25}$ In this assessment, no account was made for the role of biological growth in the capital stock of the fisheries. Table 1 supports the model because we see that higher value fisheries were more likely to be registered in order to maintain private, hierarchical control over them. Returns to governance in these cases were still positive. Unregistered fisheries had lower

was restricted. This was presumably as much for the safety of the users as the preservation of the reef or fish, though in 1888 the possession of fish killed by dynamite was rendered enough evidence for prosecution. In 1888 size restrictions were introduced for mullet, except for live use in stocking fishponds. These restrictions were codified into the code of the Republic of Hawaii in 1893, while the konohiki retained their rights. (Khil, 1978).

${ }^{24}$ The limited treasury of the new Territory was responsible for financing compensation for condemned fisheries, which limited their interest in doing so. The development of Pearl Harbor led to the first real cases for condemnation.

${ }^{25}$ In addition to being farther from the courts and the registration process, Hawaii and Maui are very young islands whose coasts slope off generally much faster than deeper than the older islands and whose reefs are not as developed as the older islands of Kauai, Oahu and Molokai. These are the same places where marginal lands were brought into dryland agriculture after $1450 \mathrm{AD}$. It is not surprising that they would have lower values for local consumption or smaller returns overall. 
Table 1 - Relative Value of Registered Fishery Konohiki Monopolies

\begin{tabular}{lccccc}
\hline Island & $\begin{array}{c}\text { Number of } \\
\text { fisheries }\end{array}$ & $\begin{array}{c}\text { Estimated value } \\
\mathbf{( \$ )}\end{array}$ & $\begin{array}{c}\text { Average est. } \\
\text { value } \mathbf{( \$ )}\end{array}$ & $\begin{array}{c}\text { Percent of } \\
\text { fisheries } \\
\text { registered }\end{array}$ & $\begin{array}{c}\text { Percent of estimated } \\
\text { value from registered } \\
\text { fisheries }\end{array}$ \\
\hline Oahu & 64 & 20,750 & 324 & 82.8 & 94.7 \\
Hawaii & 148 & 14,800 & 100 & 5.4 & 5.4 \\
Kauai & 24 & 9,900 & 413 & 33.3 & 83.8 \\
Maui & 81 & 7,350 & 91 & 33.3 & 27.2 \\
Molokai & 28 & 3,100 & 111 & 10.7 & 19.4 \\
Lanai & 4 & 400 & 100 & 50.0 & 50.0 \\
Totals & $\mathbf{3 4 9}$ & $\mathbf{5 6 , 3 0 0}$ & $\mathbf{1 6 1}$ & $\mathbf{2 8 . 9}$ & $\mathbf{5 6 . 0}$ \\
\hline \hline
\end{tabular}

Data from C.C. Crozier, Deputy Tax Commissioner (Mar 14, 1939)

than average returns and governance reverted to open access.

In 1947, another assessment occurred in which an attempt was made to include biological growth and catch effort (Khil, 1978). These results tended to produce even lower valuations than the 1939 survey. Many of the fisheries were seen as lacking commercial uses and their appraised values reflected this. The most highly valued fishery, the 270-acre Kahana fishery on Maui, generated per-acre values of $\$ 37.04$. This private fishery was operated collectively on a profit sharing basis, where all catches were divided $50 / 50$ between owners and fishermen, allowing rent extraction rather than the rent dissipation of open access. The lowest values were for less than twenty-five cents per acre. The once vital resource base had been almost entirely replaced by import goods.

The privatization of nearshore resources under konohiki management a hybrid institutional structure spanning the benefits of both decentralization and hierarchy - might have played a greater role in the development of long-term fisheries law if its commercial importance had not dwindled over the century or if enforcement had been simpler. Changing tastes, increased options for foods, and increasingly available open access fisheries all reduced the ability of this institution to function as a mechanism for $2^{\text {nd }}$ best provision. Table 2 shows the relative change in coastal fisheries versus other Hawaiian fisheries over the century. As the table moves from left to right, the fisheries move further offshore, are more commercial, and less traditional. This emphasizes the shift from local sustenance consumption for population and value derived from trade. The subtle shift in resources is captured in our model, albeit imperfectly, since trade has different potential resource value from sustenance.

The simultaneous maintenance of private and open access fisheries in proximate space increased the cost of enforcement for the konohiki, and in many cases these higher enforcement costs outweighed the benefits. The 
Table 2 - Percent of Catch by Habitat Type

\begin{tabular}{lccccc}
\hline \hline Year & $\begin{array}{c}\text { Coastal } \\
\text { (\% of total) }\end{array}$ & $\begin{array}{c}\text { Neritic-pelagic } \\
\text { (\% of total) }\end{array}$ & $\begin{array}{c}\text { Slope and Seamount } \\
\text { (\% of total) }\end{array}$ & $\begin{array}{c}\text { Pelagic } \\
\text { (\% of total) }\end{array}$ & $\begin{array}{c}\text { Total Catch } \\
\text { (Thousands of Pounds) }\end{array}$ \\
\hline $\mathbf{1 9 0 0}$ & 59.1 & 16.2 & 3.4 & 21.2 & 6157.8 \\
$\mathbf{1 9 5 0}$ \&1953 avg & 4.8 & 3.4 & 4.0 & 87.8 & 17426.7 \\
$\mathbf{1 9 8 5 - 6}$ avg & 6.1 & 5.4 & 16.8 & 71.8 & 9868.0 \\
$\mathbf{2 0 0 2 - 3}$ avg & 1.3 & 2.5 & 5.8 & 90.4 & 23398.0 \\
\hline \hline
\end{tabular}

Notes: Coastal fisheries: inshore reef fish (e.g. akule (Selar crumenopthalmus) and opelu (Decapterus spp.)); Neritic-pelagic fisheries: species are found both inshore and offshore (e.g. jacks, Ulua spp.); Slope and seamount fisheries: species are found offshore at elevated seamounts (e.g. pelagic armorhead (Pseudopentaceros richardsoni) in Hawaii, fished virtually commercial extinction in the 1980s); Pelagic fisheries: species (e.g. ahi (thunnus spp.)) found primarily offshore. Sources: Shomura (1987) and State of Hawaii Department of Land and Natural Resources, Dept of Aquatic Resources (2004).

Reporting for the 2002-3 period includes a slightly different composition of species that under-reports coastal fishes compared to earlier years. However the important shift is clear: between 1900 and 1950, coastal fisheries dwindled in comparison to the expanding pelagic fisheries.

commercial value of the in-shore fisheries they held became increasingly limited for much of the $20^{\text {th }}$ Century. Pressures for multiple uses of the areas led to some condemnations, and today, virtually all of the fisheries are operated under complex government restrictions, but open to anyone who conforms to those open-access regulations.

The co-incidental use of both "private" konohiki fisheries and increasingly regulated, open access fisheries in the $19^{\text {th }}$ and $20^{\text {th }}$ centuries illustrates the role of non-convexities and externalities in the institutional governance of resource use. Indeed, advances in aquaculture technology, such as cages, could have developed quite naturally out of the konohiki system described above. They may have been delayed in Hawaii due to required changes in federal law granting leases and uncertainty about the existence of appropriate markets for fingerlings. By abstracting from non-convexities, the standard theory suggests that increased pressure on resources due to economic growth automatically contributes to the evolution from open access towards private or centralized authority.

\subsection{Growth and Institutional Change}

Throughout the process of hierarchical consolidation, the responsibilities of the commoners changed little; each was expected to perform his farming or fishing duties under the authority of the ahupua'a konohiki. Two important trends evolved, however. First, the commoners developed specialized skills (e.g. in taro and dryland farming and various fishing techniques), enhancing resource productivity while tying them more closely to the ahupua' $a$ (Handy and Handy, 1991, p. 310ff). Second, the konohiki's role of manager evolved with increased responsibilities and specialized knowledge (e.g. organizing hukilau, irrigation and other communal activities). When the posi- 
tion of konohiki first emerged (during the expansion period), he was primarily a tax collector providing service for a superior ali $i$ in return for status and a portion of the harvests. By the time of the Great Mahele, his role had been gradually transformed into a position that claimed ownership of the resources, and the associated ability to make decisions. This presented the attractive option to separate authority and decision-making in the move to private property by leaving the management of low-value coastal resources to the konohiki, lowering governance costs of the new system.

Opportunities for exchange also promote specialization and intensification by increasing the value of the resource base. As the consumption set expands to include gains from trade and as the number of potential transactions expands, the need for central oversight of these transactions also increases. Centralization and augmentation of governance also includes the high fixed costs of transitioning to a rule of law and establishing rights to property. However, centralization brings with it the temptations of rentseeking.

We hypothesize, along with Glaeser and Shleifer (2003), that had Hawaii maintained independence as a kingdom longer after Western Contact rather than becoming part of the United States in the late 1890s, the centralization of authority and decisions would have been unstable and failed to last. Of the many Pacific Island kingdoms that developed via similar hierarchical processes to Hawaii, only Tonga remains a monarchy today. The Tongan monarchy is increasingly unstable, as population pressures that challenge longstanding mandates of land tenure ${ }^{26}$ make it difficult to resist calls for democratic reform and devolution of power; its first democratically elected prime minister took office in 2006. In our model, the inability of capital (the elite) to sufficiently increase the resource base, and increasing enforcement costs from a growing population trading the resource base for other sustenance make hierarchical control more costly. Indeed, the system is full cycle: the history of Pacific Island exploration is an outcropping of these challenges; until tradable goods and technology from the West decreased the severity of the connection between the resource base and the human population, new island settlements stemmed from rafts leaving crowded islands to an unknown, risky fate - journeys that were chosen as an alternative to direct human sacrifice (Kirch, 2002).

According to the theory set forth above and in line with our model results, efficient governance becomes more centralized as an economy grows, while efficient decision-making becomes first more centralized then more decentralized. An alternative path, where decision-making also continues to become more centralized, is not expected to be optimal as the constitutional agency costs shift to favor a system that minimizes governance costs at a higher governance level, capable of sustaining higher resource pres-

${ }^{26}$ Each male at age 16 is to receive 8.25 acres (U.S. Department of State Background Note, Tonga, 2003). 
sures. Furthermore, within every institutional framework, governance efforts increase in response to benefits of greater specialization, intensification and greater resource scarcity. The Hawaiian record is consistent with this perspective.

\section{Conclusions}

We provide a dynamic theory of property rights focused on the co-evolution of governance, specialization, intensification, and economic growth. In particular, we elucidate the dynamic foundations needed for a complete theory of second-best resource management through a model of a resource dependent economy in which we distinguish governance of the resource stock from enforcement of decisions to use the resource stock for funding a governing elite (or capital accumulation) and/or external trade within an institution. These distinctions enable us to illustrate governance tradeoffs amongst institutional options across three developmental phases of growth: extensive growth, internal growth and capitalization, and external trade. Our model shows, and is supported by the evidence for Hawaii, that the elite forms in response to needs for governing the resource base, and expands according to its ability to 'pay for itself' through governance that translates to growth in the laborer population, resource stock, and elite.

We further examine transitions amongst the phases and implications of dynamic changes in the level of resource dependence of the economy through trade. Trade that introduces considerable technological changes not only transforms the relative values of the resource base for different uses, it weakens the linkage between the human and resource populations in ways that capital accumulation alone cannot. We have also sketched a categorical theory explaining why, as the benefits of resource management increase with population pressure or other causes of specialization, governance costs increase both within and across institutions. A methodological point of possible interest is that second-best analysis cannot proceed without first-best analysis. Indeed this is implicit in Coasean analysis. It is precisely the proposition that, absent transaction costs, different institutions are capable of the same first-best solution, which allows us to use the first-best solution as a benchmark against which the transaction costs of alternative institutions can be compared ${ }^{27}$

More specifically, with respect to alternative solutions to the open access problem, we have shown that open access can be at least a second-best, if not a first-best, solution. This is the case in early Hawaiian history, when resource pressures were low, and though the kapu institution was available as it was brought with the first settlers, its use was expectedly minimal. Even

${ }^{27}$ For this to be generally true, we must use transaction costs in its broadest sense, i.e. that transaction costs are the costs of running the economic system and are the equivalent of friction in physical systems (Williamson, 1985). 
if open access is first-best inefficient, it is not necessarily the case that open access is inferior to at least one of the three proposed alternatives; it can be second-best efficient. Indeed, we have suggested that there is a second-best transition, as the optimal degree of specialization increases, from open access to common property management to private property, which helps to explain the governmental Kuznets curve illustrated in Figure 2.

The second-best theory of induced institutional change predicts an increase in conservation effort as population pressure and modernization deplete natural resources. Unlike previous theoretical frameworks, the suggested theory allows for changing resource extraction (or changing investment) over time, and in our model, the formation of the governing elite and/or the capital needed for expanding the resource base are endogenous. We witness this increase in conservation effort in Hawaii along with institutional development that benefits from the ability of hierarchy to capture economies of scale in land and resource management, and then seeks to benefit from the change in relative benefits by decentralizing decision-making into the hands of the konohiki rather than the king. The increase in governance and the institutional change from open access to the intermediate ahириа' $a$ system, and later to a centralized system, accord with second-best theory. Religion and brutal hierarchical control were used effectively to enforce limited access at relatively low cost.

While the co-evolution of intensification, specialization, and consolidation are consistent with second-best theory, subsequent developments require third-best analysis. For example, while centralized governance was initially effective at resource conservation (under King Kamehameha I), the inherent opportunities for rent-seeking were exploited by King Kamehameha II (Liholiho) and subsequent rulers. The intervention of Western culture and politics created an additional third-best force at odds with efficient institutional change. Western influence stressed the hierarchical system in at least two ways. First, it provided opportunities for specialization and trade beyond ahupua' $a$ boundaries that were not readily captured under ahupua'a governance. Second, Western contact increased the benefits of extracting labor taxes from the commoners in order to import status goods.

From Hawaiian history, we garner three potential trends in institutional evolution. First, each institutional framework has some flexibility in accommodating increased governance. Governance within an institutional system can respond to changes in resource pressures, albeit large changes in relative values and costs may occasion a transition to new institutions. Furthermore, different governance and enforcement efforts have different effects on the economy's evolution. Increasing harvest governance, for example, may make the available harvest larger without increasing the availability of capital. Subsequently, we see continued evidence of the ways in which resource use intensifies and develops, creating economic growth, even with population decline rather than growth. Finally, institutions do not simply switch 
instantaneously from one form to another, even when they are seemingly imposed. The example of the konohiki's slow transition from a minion of the al ${ }^{\prime} i$, to an incentive-driven resource owner, shows the shift from manager to owner that accompanies a shift from a common property regime to a private property one.

As Hawaii's population increased, production systems were intensified. Social organization became increasingly complex, accommodating increasing division of labor. The increased vertical and horizontal specialization was facilitated by new incentive and governance structures summarized by the governmental Kuznets curve. Specifically, we witness a natural progression from a small, 'ohana network of reciprocal exchange, managed by a clan chief, to an increasingly stratified hierarchy that resulted in a monarchy in 1805. Most recently, this progression has been equated with development of statehood on the same terms as Egypt, Mesopotamia, Mesoamerica, Incan Civilization, Indus Civilization, and China (Hommon, 2013).

With Western Contact, relative resource values diverge greatly from the past, and a new path toward decentralization of decision-making begins while centralization of authority is transferred from one institutional framework to another but continues to intensify, despite the decline of population. With respect to marine property, this increasingly centralized authority is evidenced in the increasing adoption of open-access fishing restrictions. At the same time the government foregoes its previous rights to shares of the near-shore catch, which is dwindling in economic importance.

We see increased governance and development of hierarchy as populations grow. In addition, it follows that the value of marginal land, as the land is being cleared with population growth and added to the resource base, satisfies the condition that the cost of clearing equals the present value of implicit rents that it earns in the future. In this case, the marginal user cost of land as capital is constant until the land frontier is reached and intensification begins. With even greater population pressure, intensification and resource depletion, however, potential gains from trade across districts increase (LaCroix and Roumasset, 1984) and the dictatorial hierarchies controlling each ahupua' $a$ economy were not well suited to exploit those opportunities. If such potential gains are large enough to warrant the increased governance costs of further centralization of authority (albeit not necessarily of decision-making), the second-best theory predicts that such institutional change will take place. At the time of Western Contact, Hawaii was headed for just this sort of unification of authority.

Inasmuch as Western institutions were exogenously imposed, we cannot be sure that hierarchical authority would have eventually withered away and been replaced by market institutions. Without the significant decline in the native population, and the resulting ease in transferring the resource base to export commodities, the demands of the resource-based economy for sustenance might have changed the dynamics considerably. Consider- 
able specialization and exchange was possible within the hierarchical system. The development of the position of konohiki as a specialized land manager, and then its transformation into resource owner, exemplifies the interdependence of specialized skills and productivity, which intensifies along with institutional change.

To the extent that inter-district trade is facilitated by centralized authority and decentralized decisions, two questions arise that may be suitable for further research. First, can the decentralization of decision-making evolve from the top-down system of medieval Europe or pre-contact Hawaii without violence or external force? Second, where decision-making is centralized as well as authority, e.g. as in socialism, is it prudent to transition directly to decentralized exchange at the national level or is devolving central authority to a sub-national level a useful intermediate step?

We hope that the theory provided here is found to be applicable elsewhere. While we have emphasized the role of efficiency in determining the coevolution of production and governance, extended models will have a less deterministic flavor. In particular, the balance of rent-seeking and efficiency will vary according to specific circumstances. While replacement of the Hawaiian monarchy by private property was accelerated by coincidence, other economies may exhibit more institutional inertia. Shocks to population (e.g. from disease), changing international demands and the transaction costs of trade, and shocks to the resource base itself, e.g. via invasive species, are natural candidates to explore in numerical analysis. 


\section{References}

Abbott, I.A., 1992. Laau Hawaii: Traditional Hawaiian Uses of Plants. Honolulu, HI, Bishop Museum Press.

Acemoglu, D., Egorov, G., Sonin, K., 2012. Dynamics and Stability of Constitutions, Coalitions and Clubs. American Economic Review 1024, 14461476. http://dx.doi.org/10.1257/aer.102.4.1446

Acemoglu, D., Egorov, G., Sonin, K., 2012. Political Model of Social Evolution. PNAS 1084, 21292-21296.

Anderson, T.L., Hill, P.J., 1990. The Race for Property Rights. Journal of Law and Economics 33, 177-197. http://dx.doi.org/10.2307/725514

Anderson, T.L., Hill, P.J., 1975. The Evolution of Property Rights: A Study of the American West. Journal of Law and Economics 18, 163-179. http://dx.doi.org/10.1086/466809

Bardhan, P.K., Srinivasan, T.N. 1971. Cropsharing Tenancy in Agriculture: A Theoretical and Empirical Analysis. American Economic Review 611, 48-64.

Brander, J.A., Taylor, M.S., 1998. The Simple Economics of Easter Island: A Ricardo-Malthus Model of Renewable Resource Use. The American Economic Review 881, 119-138.

Clark, C., 2005. Mathematical Bioeconomics: Optimal Management of Renewable Resources, 2nd Ed. Wiley-Interscience.

Clark, C., Munro, G., 1975. The Economics of Fishing and Modern Capital Theory: A Simplified Approach. Journal of Environmental Economics and Management 2, 92-106. http:/ / dx.doi.org/10.1016/0095-0696(75)90002-9

Davis, L., North, D., 1971. Institutional Change and American Economic Growth. Cambridge, Cambridge University Press.

Demsetz, H., 1967. Toward a Theory of Property Rights. American Economic Review papers and proceedings 57, 347-359.

Field, B.C., 1989. The Evolution of Property Rights. Kyklos 423, 319-345. http://dx.doi.org/10.1111/j.1467-6435.1989.tb00197.x

Finney, B.R., Houston, J.D., 1996. Surfing: A History of the Ancient Hawaiian Sport. Pomegranate. 
Fisk, E.K., Shand, R.T., 1970. The Early Stages of Development in a Primitive Economy: Evolution from Subsistence to Trade and Specialization. In Subsistence Agriculture and Economic Development, C.R. Walton, pp. 257-274.

Glaeser, E.L., Shleifer, A., 2003. The Rise of the Regulatory State. Journal of Economic Literature 412, 401-425. http:/ / dx.doi.org/10.1257/jel.41.2.401

Handy, E.S, Handy, E.G., Pukui, M.K., 1991. Native Planters in Old Hawaii: Their Life, Lore, and Environment. Revised Ed. Honolulu, HI, Bishop Museum Press.

Hommon, R.J., 1975. Use and Control of Hawaiian Inter-Island Channels Polynesian Hawaii: AD 1400-1794. Honolulu, HI, Office of the Governor.

Hommon, R.J., 2013. The Ancient Hawaiian State: Origins of a Political Economy. Oxford University Press. http://dx.doi.org/10.1093/acprof:oso/9780199916122.001.0001

Jensen, M.C., Meckling, W.H., 1976. Theory of the Firm: Managerial Behavior, Agency Costs and Ownership Structure. Journal of Financial Economics 34, 305-360. http:/ / dx.doi.org/10.1016/0304-405X(76)90026-X

Kame'eleihiwa, L., 1992. Native Land and Foreign Desires. Honolulu, HI: Bishop Museum Press.

Khil, J., 1978. Evolution of Sea Fishery Rights and Regulations in Hawaii and their Implications for Conservation. Unpublished manuscript Honolulu, HI, University of Hawaii.

Kikuchi, W., 1976. Prehistoric Hawaiian Fishponds. Science 193, 295-299. http://dx.doi.org/10.1126/science.193.4250.295

Kikuchi, W., 1973. Hawaiian Aquacultural System. Ph.D. Dissertation, University of Arizona Dept. of Anthropology. Ann Arbor, MI, University of Michigan Press

Kirch, P.V., 2007. Hawaiian Biocomplexity Project. Available at : http://sscl.berkeley.edu/ oal/pdf/biocomplexity.pdf

Kirch, P.V., 2005. Results of Prior NSF Support Under BCS-0119819. Online report available at: http://www.hawaii-biocomplexity.org/

Kirch, P.V., Hartshorn, A.S., Chadwick, O.A., Vitousek, P.M., Sherrod, D.R., Coll, J., Holm, L., Sharp, W.D., 2004. Environment, Agriculture, and Settlement Patterns in a Marginal Polynesian Landscape. PNAS 10126, 99369941. http://dx.doi.org/10.1073/pnas.0403470101 
Kirch, P. V., 2002. On the Road of the Winds-An Archaeological History of the Pacific Islands Before European Contact. University of California Press.

Kirch, P.V., 1996. Legacy of the Landscape: An Illustrated Guide to Hawaiian Archaeological Sites. Honolulu: University of Hawaii Press.

Kirch, P. V., 1985. Feathered Gods and Fishhooks: An Introduction to Hawaiian Archaeology and Prehistory. Honolulu, HI, University of Hawaii Press.

Kuykendall, R.S., 1938. The Hawaiian Kingdom, Vol. 1. Honolulu: University of Hawaii Press.

LaCroix, S., Roumasset, J., 1984. An Economic Theory of Political Change in Premissionary Hawaii. Explorations in Economic History 21, 151-168. http://dx.doi.org/10.1016/0014-4983(84)90022-6

Ladefoged, T.N., Graves, M.W., 2008. Variable Development of Dryland Agriculture in HawaiE $\hat{E}$. Current Anthropology 495, 771-802. http://dx.doi.org/10.1086/591424

Ladefoged, T., Graves, M.W., Jennings, R.P., 1996. Dryland Agricultural Expansion and Intensification in Kohala, Hawai'i Island. Antiquity 70, 861880.

Ladefoged, T., 1993. Hawaiian Dryland Agricultural Intensification and the Pacific Economy. Pacific Studies, 162, 119-131.

Libecap, G.D., 1978. Economic Variables and the Development of the Law: The Case of Western Mineral Rights. The Journal of Economic History 38, 338-362. http://dx.doi.org/10.1017/S0022050700105121

Libecap, G., 1989. Contracting for Property Rights. Cambridge, Cambridge University Press.

Libecap, G., Wiggins, S.N., 1985. The Influence of Private Contractual Failure on Regulation: The Case of Oil Field Unitization. Journal of Political Economy 4, 690-714. http://dx.doi.org/10.1086/261326

Lueck, D., 2002. The Extermination and Conservation of the American Bison. Journal of Legal Studies 312, S609-S652. http:/ /dx.doi.org/10.1086/340410

McClenachan, L., Kittinger, J.N., 2013. Multicentury Trends and the Sustainability of Coral Reef Fisheries in Hawai'i and Florida. Fish and Fisheries 14, 239-255. http:/ /dx.doi.org/10.1111/j.1467-2979.2012.00465.x 
North, D., Thomas, P., 1973. The Rise of the Western World: a New Economic History. Cambridge University Press. http://dx.doi.org/10.1017/CBO9780511819438

Olson, M., 1965. The Logic of Collective Action. Cambridge: Harvard University Press.

Ostrom, E., 1990. Governing the Commons: Evolution of Institutions for Collective Action. Cambridge, Cambridge University Press. http://dx.doi.org/10.1017/CBO9780511807763

Roumasset, J., 1995. The Nature of the Agricultural Firm. Journal of Economic Behavior and Organization 26, 171-177. http:/ /dx.doi.org/10.1016/0167-2681(94)00007-2

Roumasset, J., 2008. Population and Agricultural Growth. The New Palgrave Dictionary of Economics. Second Edition. Eds. Steven N., Durlauf, L.E., Blume. Palgrave Macmillan. http://dx.doi.org/10.1057/9780230226203.1308

Shomura, R.S., 1987. Hawaii's Marine Fishery Resources: Yesterday 1900 and Today 1986. Administrative Report H-87-21 December 1987. Honolulu, HI: Southwest Fisheries Center, National Marine Fisheries Service Honolulu Laboratory.

Taylor, M.S., 2011. Buffalo Hunt: International Trade and the Virtual Extinction of the North American Bison. American Economic Review 1017, 3162-3195. http://dx.doi.org/10.1257/aer.101.7.3162

Vitousek, P.M., Ladefoged, T.N., Kirch, P.V., Hartshorn, A.S., Graves, M.W., Hotchkiss, S.C., Tuljapurkar, S., Chadwick, O.A., 2004. Soils, Agriculture, and Society in Precontact Hawai'i. Science 304, 1665-1669. http://dx.doi.org/10.1126/science.1099619

Witt, U., 1987. The Demsetz Hypothesis on the Emergence of Property Rights Reconsidered. In: R., Pethig, U., Schlieper (Eds.), Efficiency, Institutions, and Economic Policy. Heidelberg: Springer-Verlag. 